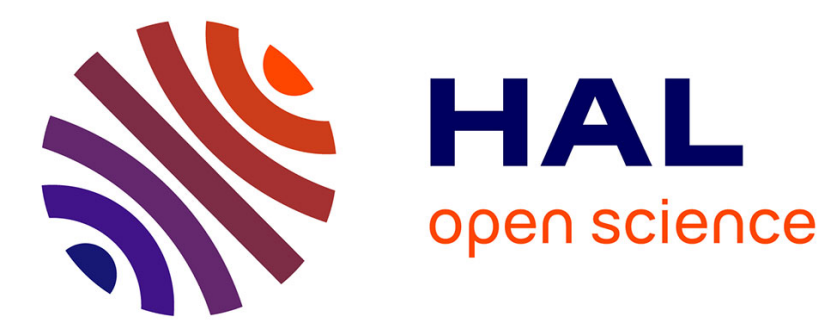

\title{
Learning, robust monetary policy and the merit of precaution
}

Marine Charlotte André, Meixing Dai

\section{To cite this version:}

Marine Charlotte André, Meixing Dai. Learning, robust monetary policy and the merit of precaution. B.E. Journal of Macroeconomics, 2018, 18 (2), 21 p. 10.1515/bejm-2016-0236 . hal-03030047

\section{HAL Id: hal-03030047 https://hal.science/hal-03030047}

Submitted on 29 Nov 2020

HAL is a multi-disciplinary open access archive for the deposit and dissemination of scientific research documents, whether they are published or not. The documents may come from teaching and research institutions in France or abroad, or from public or private research centers.
L'archive ouverte pluridisciplinaire HAL, est destinée au dépôt et à la diffusion de documents scientifiques de niveau recherche, publiés ou non, émanant des établissements d'enseignement et de recherche français ou étrangers, des laboratoires publics ou privés. 


\title{
Marine Charlotte André 1 / Meixing Dai ${ }^{2}$
}

\section{Learning, robust monetary policy and the merit of precaution}

\author{
${ }^{1}$ Université de Strasbourg, CNRS, BETA UMR 7522, 61, Avenue de la Forêt Noire, 67085 Strasbourg Cedex, France, E-mail: \\ andrem@unistra.fr. http://orcid.org/0000-0003-4554-7598. \\ ${ }^{2}$ Université de Strasbourg, CNRS, BETA UMR 7522, F-67000 Strasbourg, France
}

\begin{abstract}
:
We study in a New Keynesian framework the consequences of adaptive learning for the design of robust monetary policy. Compared to rational expectations, the fact that private sector follows adaptive learning gives the central bank an additional intertemporal trade-off between optimal behavior in the present and in later periods thanks to its ability to manipulate future inflation expectations. We show that adaptive learning imposes a more restrictive constraint on monetary policy robustness to ensure the dynamic stability of the equilibrium than under rational expectations but strengthens the argument in favor of a more aggressive monetary policy when the central bank fears for model misspecifications.
\end{abstract}

Keywords: adaptive learning, model uncertainty, optimal monetary policy, robust control

JEL classification: C62, D83, D84, E52, E58

DOI: 10.1515/bejm-2016-0236

\section{Introduction}

A great challenge for the central bank (CB) is to conduct monetary policy with limited understanding of many key features of the macroeconomic environment that quickly evolves over times. Facing such a challenge, the $\mathrm{CB}$ is likely to prefer basing monetary policy on principles that are also valid if the assumptions of the model differ from reality. In other words, monetary policy should be robust to plausible deviations from the benchmark model as suggests the robust control approach instigated by Hansen and Sargent (Hansen and Sargent 2001; 2003; 2007). By introducing model uncertainty, this approach focuses on the worst-case outcome within a set of admissible models as economic agents are not able to attribute probabilities to all plausible outcomes. In the sense of Hansen and Sargent, robust monetary policies are designed to perform well in worst-case scenarios by minimizing the consequences of the worst-case specification of the policymaker's reference model.

One important implication of this approach for the conduct of monetary policy is that the attenuation principle under uncertainty well known since Brainard (1967) may not always hold. ${ }^{1}$ The concern about worst-case scenarios leads the CB to amplify rather than attenuate the response of optimal monetary policy to shocks in a closed economy (e.g. Giannoni and Woodford 2002; Onatski and Stock 2002; Giordani and Söderlind 2004; Leitemo and Söderström 2008; Gonzalez and Rodriguez 2013) and implies that the CB takes stronger action to avoid particularly costly outcomes. This can generate inflation persistence (Qin, Sidiropoulos, and Spyromitros 2013) and justify the appointment of a liberal central banker if the latter has a greater concern about misspecifications of the Phillips curve (Dai and Spyromitros 2010). In contrast, a conservative central banker would be preferable when concern for misspecifications of the true degree of shock persistence or these of the output gap was considered (Tillmann 2009; 2014). These theoretical results give rise to some insightful prescriptions regarding the conduct of monetary policy. However, the usefulness of such prescriptions could be limited by the fact that they are obtained under the hypothesis of rational expectations (RE). The reason of this is that this hypothesis is excessively demanding for private agents in terms of knowledge and understanding about the structure of the economy as well as capability of data collecting and processing, particularly when the economic environment is uncertain. ${ }^{2}$

Facing model uncertainty, private agents may not be able to properly forecast how economic variables evolve, and their understanding of the economy and their expectations could be better described by a learning process instead of the RE hypothesis. ${ }^{3}$ Such a process reflects the limited rationality of private agents. The advent of the learning hypothesis poses a fundamental challenge to monetary policy decisions. The latter should account for the implications of learning because when agents are learning, optimal monetary policy with RE can perform 
poorly (Milani 2008; Orphanides and Williams 2008). As highlighted by Schmidt-Hebbel and Walsh (2009), a key lesson learned from the research on monetary policy is that neither uncertainty nor learning can be ignored. The implications of learning for monetary policy are examined by a developing body of literature showing that learning on the one hand helps selecting between all the possible equilibria obtained under RE, and on the other hand can be considered as a process converging towards RE (Airaudo, Nisticò, and Zanna 2015; Bullard and Mitra 2002; da Gama Machado 2013; Evans and Honkapohja 2003; 2006). Besides, it is recognized that forecasting under the assumption of learning in DSGE models outperforms forecasting under the RE hypothesis (Slobodyan and Wouters 2012). Another advantage of learning is that it resolves the disinflationary-booms anomaly in the New Keynesian model under RE (Moore 2016).

The present study contributes to the literature on robust monetary policy by studying the implications for monetary policy of concern for model misspecifications when private agents form expectations using adaptive learning. The latter can be seen as the consequences of limited access by private agents to the information set. The intention of the paper is to examine the implications of learning with a constant-gain algorithm for robust monetary policy. We show that adaptive learning strengthens the argument in favor of a more aggressive monetary policy that is advocated in misspecified models with RE. Our paper complements Molnár and Santoro (2014), who investigate optimal monetary policy when agents are learning in the benchmark New Keynesian model and consider the robustness of their results when the learning process is misspecified. ${ }^{4}$ Our paper is also related to Orphanides and Williams (2007) who show that monetary policy robust to misperceptions of the natural interest rate raises the persistence of inflation, and to Bask and Proaño (2016) who find that an incorrect assessment of the cost channel and the degree of inflation persistence by the CB greatly affects its capability to enforce a determinate and learnable RE equilibrium. ${ }^{5}$ Both of these papers consider least square learning. In contrast, we assume that model equations are misspecified while ignoring the concern for misspecification of the learning process, and we look for the analytical equilibrium solutions under constant-gain learning.

The remainder of the paper is structured as follows. Section 2 outlines the model. Section 3 derives equilibrium solutions under monetary policy discretion in both cases of RE and constant-gain learning. Section 4 explores the effects of learning on robust monetary policy. Section 5 discusses some possible extensions. Section 6 concludes.

\section{The model}

We consider two deviations from the standard New Keynesian model that has undoubtedly become the workhorse in the recent literature on monetary policy (Rotemberg and Woodford 1997; Clarida, Gali, and Gertler 1999). The first is a sequential min-max game between the nature (malevolent agent) setting the model misspecifications to maximize the social loss and the $\mathrm{CB}$ who sets robust monetary policy to minimize the social loss. The CB and the malevolent agent play a Nash game, meaning that their choice is optimal given the other player's choice. ${ }^{6}$ The second is the adaptive learning behavior of the private sector when forming expectations.

\subsection{Aggregate demand and supply}

The New Keynesian Phillips curve is modified by introducing a misspecification term $h_{t}$ :

$$
\pi_{t}=\beta E_{t}^{*} \pi_{t+1}+\kappa x_{t}+e_{t}+h_{t}
$$

where $0<\beta<1$ stands for the discount factor, $x_{t}$ the output gap and $\pi_{t}$ inflation; $\kappa$ is a composite parameter, i.e. $\kappa \equiv \frac{(1-\vartheta)(1-\vartheta \beta)}{\vartheta}(1+\varphi)$, with $\varphi$ representing the inverse of the steady-state elasticity of labor supply and $\vartheta$ the share of firms that do not optimally adjust but simply update in period $t$ their previous price by the steady-state inflation rate. The composite parameter $\kappa$ is the output-gap elasticity of inflation and captures the effects of the output gap on real marginal costs and thus on inflation. The expectation operator $E_{t}^{*}$ represents private agents' expectations conditional on information set available at time $t$, with the asterisk reflecting the fact that these agents may form RE or not. The noise $e_{t} \sim N\left(0, \sigma_{e}^{2}\right)$ is an iid cost-push shock. The inflation misspecification, $h_{t}$, is controlled by a fictitious "malevolent agent" in the sense of Hansen and Sargent (2007), symbolizing the policy maker's worst fears about specification errors. The malevolent agent's budget constraint is:

$$
E_{t} \sum_{i=0}^{+\infty} \beta^{i} h_{t+j}^{2} \leq \chi_{t}^{2}
$$


where $\chi_{t}^{2}$ represents the budget allocated by the CB to the malevolent agent to create misspecifications.

The New Keynesian IS equation is given by

$$
x_{t}=E_{t}^{*} x_{t+1}-\sigma^{-1}\left(r_{t}-E_{t}^{*} \pi_{t+1}\right),
$$

where $r_{t}$ is the nominal short-term interest rate and $\sigma$ the risk aversion of households. To simplify the analysis, we assume there is no demand shock and misspecification in the IS equation since the CB can neutralize shocks affecting the aggregate demand by optimally setting the interest rate.

\subsection{Monetary policy objectives}

The $\mathrm{CB}$ is assumed to have the same preferences for inflation and output-gap stabilization as the society, whose expected social loss function is given by:

$$
L_{t}^{s}=\frac{1}{2} E_{t} \sum_{i=0}^{+\infty} \beta^{i}\left(\pi_{t+i}^{2}+\alpha x_{t+i}^{2}\right),
$$

where $\alpha>0$ denotes the relative weight assigned to the objective of output-gap stabilization. To simplify, we assume that inflation target is equal to zero. The overly ambitious output target, which is common in the BarroGordon framework, is absent in (4), i.e. output-gap target is also equal to zero. Thus, discretionary monetary policy set to minimize social loss (4) would avoid an average inflation bias.

Under discretion, the CB designs a robust monetary policy that takes account not only of shocks affecting the economy but also of model misspecifications reflecting the worst possible model within a given set of plausible ones. $^{7}$

The optimal robust monetary policy is obtained by solving the min-max problem:

$$
\min _{r_{t}} \max _{h_{t}} L_{t}^{C B}=\frac{1}{2} E_{t} \sum_{i=0}^{+\infty} \beta^{i}\left(\pi_{t+i}^{2}+\alpha x_{t+i}^{2}-\theta h_{t+i}^{2}\right),
$$

subject to the misspecified Phillips curve (1) and the malevolent agent's budget constraint (2). The penalty parameter $\theta>0$ controls the preference for robustness. The misspecification errors $h_{t}$ are inversely proportional to $\theta$. The absence of concern for robustness corresponds to the case where $\theta \rightarrow \infty$, implying that $h_{t} \rightarrow 0$. In the following, we assume for simplicity that the malevolent agent's budget constraint (2) is not binding.

\subsection{Learning rules of private agents}

While the CB is facing uncertainty, private agents also find it hard to know the actual law of motion (ALM) for inflation and the output gap such that they learn the latter's evolution using an algorithm. ${ }^{8}$ Thus, they recursively estimate a Perceived Law of Motion (PLM), i.e. a noisy steady state in the terminology of Evans and Honkapohja (2001), which is consistent with the law of motion that the CB would follow under RE. Indeed, private agents believe that the steady-state levels of inflation and the output gap only depend on iid cost-push shocks and hence perceive their expected levels as constant, knowing that the conditional and unconditional expectations of these variables are identical. This justifies that private agents estimate these variables via sample means.

Private agents form their expectations using the following learning algorithms (Marcet and Nicolini 2003):

$$
\begin{aligned}
& E_{t}^{*} \pi_{t+1} \equiv a_{t}=a_{t-1}+\gamma_{t}\left(\pi_{t-1}-a_{t-1}\right), \\
& E_{t}^{*} x_{t+1} \equiv b_{t}=b_{t-1}+\gamma_{t}\left(x_{t-1}-b_{t-1}\right),
\end{aligned}
$$

where $0 \leq \gamma_{t} \leq 1$ represents a deterministic sequence of learning gains that defines the speed of integration of new data into expectations with exogenously given $a_{0}$ and $b_{0}$. If $\gamma_{t} \rightarrow 0$, the policymakers cannot manipulate future expectations by changing the current policy. The underlying learning mechanism means that inflation (output-gap) expectations are increasing with last period inflation (output gap). ${ }^{9}$ To ensure the analytical 
tractability of the model, we choose to adopt constant-gain learning, i.e. $\gamma_{t+1}=\gamma_{t}=\gamma$. Moreover, the latter better fits time-varying environments. As extensively discussed in the learning literature (Evans and Honkapohja 2009), private agents would be more inclined to use a constant-gain learning algorithm if they believe in possible structural changes to happen in the near future. ${ }^{10}$

\section{The equilibrium under discretionary monetary policy}

Learning gives us an attractive alternative way of conceiving how private agents interact with monetary authority compared to the RE hypothesis. It considerably affects the CB's trade-off between inflation and the output gap by giving rise to an incentive for the $C B$ to decrease the volatility of current inflation as well as a greater room of maneuver to achieve this ${ }^{11}$.

\subsection{Rational expectations equilibrium}

We use the RE equilibrium (REE) solution as a benchmark to illustrate how the equilibrium is modified by an optimal monetary policy designed with private agents' beliefs being taken into account. The CB solves its min-max problem (5) subject to (1). This leads to:

$$
\pi_{t}=-\frac{\alpha}{\kappa} x_{t}
$$

The targeting rule (8) indicates that the trade-off between $\pi_{t}$ and $x_{t}$ is not affected by model misspecifications. Solving (1)-(3) and (8) yields the ALMs for inflation and the output gap, and the interest rate rule that implements the optimal monetary policy as follows:

$$
\begin{gathered}
\pi_{t}=\frac{\alpha \theta \beta}{\theta\left(\alpha+\kappa^{2}\right)-\alpha} E_{t}^{*} \pi_{t+1}+\frac{\alpha \theta}{\theta\left(\alpha+\kappa^{2}\right)-\alpha} e_{t}, \\
x_{t}=-\frac{\kappa \theta \beta}{\theta\left(\alpha+\kappa^{2}\right)-\alpha} E_{t}^{*} \pi_{t+1}-\frac{\kappa \theta}{\theta\left(\alpha+\kappa^{2}\right)-\alpha} e_{t} \\
r_{t}=\sigma E_{t}^{*} x_{t+1}+\left(1+\frac{\sigma \kappa \theta \beta}{\theta\left(\alpha+\kappa^{2}\right)-\alpha}\right) E_{t}^{*} \pi_{t+1}+\frac{\sigma \kappa \theta}{\theta\left(\alpha+\kappa^{2}\right)-\alpha} e_{t} .
\end{gathered}
$$

The ALMs (9)-(11) correspond to the monetary policy set by a policymaker who does not take into account how other economic agents revise their beliefs. To ensure that $\pi_{t}$ increases with $E_{t}^{*} \pi_{t+1}$ and $e_{t}$, the CB must limit its preference for robustness so that $\theta\left(\alpha+\kappa^{2}\right)-\alpha>0$, i.e. ${ }^{12}$

$$
\theta>\frac{\alpha}{\alpha+\kappa^{2}}
$$

The system composed of (1), (3) and (8) has a unique non-explosive REE solution in terms of the only state variable $e_{t}$, known as the "minimal state variable" solution (McCallum 1983). Thus, under RE, the solution of $\pi_{t}$ takes the following form: $\pi_{t}=\zeta e_{t}$. The formation of RE conditional on the available information at $t$ leads to $E_{t}^{*} \pi_{t+1}=E_{t} \pi_{t+1}=\zeta E_{t} e_{t+1}=0$. Substituting $E_{t} \pi_{t+1}=0$ into (9)-(11) leads to the REE solution:

$$
\begin{gathered}
\pi_{t}=\frac{\alpha \theta}{\theta\left(\alpha+\kappa^{2}\right)-\alpha} e_{t}, \\
x_{t}=-\frac{\kappa \theta}{\theta\left(\alpha+\kappa^{2}\right)-\alpha} e_{t}, \\
r_{t}=\frac{\sigma \kappa \theta}{\theta\left(\alpha+\kappa^{2}\right)-\alpha} e_{t} .
\end{gathered}
$$


It is straightforward to see from (9)-(11) that a decrease in $\theta$ (i.e. a greater preference for robustness) implies a more aggressive response of the $\mathrm{CB}$ to cost-push shocks or a change in inflation expectations, meaning that the $\mathrm{CB}$ becomes more cautious for fear of model misspecifications. Such policy response makes inflation, the output gap and the interest rate more volatile in the worst-case model. When $\theta \longrightarrow \infty$, the CB's concern for model robustness disappears and we obtain again the results corresponding to the standard New Keynesian model under the RE hypothesis. ${ }^{13}$

\subsection{Learning equilibrium}

Learning allows the CB to add an intertemporal trade-off between optimal behavior in $t$ and in later periods, generated by its ability to manipulate future inflation expectations. Current monetary policy decisions, given their effects on future inflation expectations, should take into account future intratemporal trade-offs between inflation and the output gap. We assume here that the CB exactly knows the learning algorithms followed by private agents when setting the monetary policy.

The CB's policy decision results from solving the min-max problem (5) subject to (1)-(3) in which $E_{t}^{*} x_{t+i+1}$ is substituted by $b_{t+i}$ and $E_{t}^{*} \pi_{t+i+1}$ by $a_{t+i}$, and to (6)-(7). The Lagrangian of the CB's min-max problem is:

$$
\begin{aligned}
\min _{\Psi} \max _{h_{t}} \mathscr{L}_{t}^{C B}= & E_{t} \sum_{i=0}^{+\infty} \beta^{i}\left\{\frac{1}{2}\left[\pi_{t+i}^{2}+\alpha x_{t+i}^{2}-\theta h_{t+i}^{2}\right]-\lambda_{1, t+i}\left[\pi_{t+i}-\beta a_{t+i}-\kappa x_{t+i}-u_{t+i}-h_{t+i}\right]\right. \\
& -\lambda_{2, t+i}\left[x_{t+i}-b_{t+i}+\sigma^{-1}\left(r_{t+i}-a_{t+i}\right)\right]-\lambda_{3, t+i}\left[a_{t+i+1}-a_{t+i}-\gamma\left(\pi_{t+i}-a_{t+i}\right)\right] \\
& \left.-\lambda_{4, t+i}\left[b_{t+i+1}-b_{t+i}-\gamma\left(x_{t+i}-b_{t+i}\right)\right]\right\} .
\end{aligned}
$$

where $\Psi \equiv\left\{r_{t}, \pi_{t}, x_{t}, a_{t+1}, b_{t+1}\right\}$. Deriving (16) with respect to $r_{t}, h_{t}, \pi_{t}, x_{t}, a_{t+1}$ and $b_{t+1}$ yields the first-order conditions:

$$
\begin{gathered}
\lambda_{2, t}=0, \\
-\theta h_{t}+\lambda_{1, t}=0, \\
\pi_{t}-\lambda_{1, t}+\gamma \lambda_{3, t}=0, \\
\alpha x_{t}+\kappa \lambda_{1, t}-\lambda_{2, t}+\gamma \lambda_{4, t}=0, \\
\lambda_{3, t}-E_{t}\left[\beta^{2} \lambda_{1, t+1}+\frac{\beta}{\sigma} \lambda_{2, t+1}+\beta \lambda_{3, t+1}(1-\gamma)\right]=0, \\
\lambda_{4, t}-E_{t}\left[\beta \lambda_{2, t+1}+\beta \lambda_{4, t+1}(1-\gamma)\right]=0 .
\end{gathered}
$$

Substituting $\lambda_{2, t}=0$ given by (17) into (22) leads to $\lambda_{4, t}=\beta(1-\gamma) E_{t} \lambda_{4 t+1}$, of which the only bounded forwardlooking solution is $\lambda_{4, t}=\lambda_{4, t+1}=0$. Using these results into (20) yields $\lambda_{1, t}=-\frac{\alpha}{\kappa} x_{t}$ and $\lambda_{1, t+1}=-\frac{\alpha}{\kappa} x_{t+1}$. Substituting $\lambda_{1, t}=-\frac{\alpha}{\kappa} x_{t}$ into (19), we get:

$$
\pi_{t}+\frac{\alpha}{\mathcal{K}} x_{t}+\gamma \lambda_{3, t}=0
$$

When the expectations are exogenous and constant, i.e. $\gamma=0$, the above rule is identical to the one given by (8), which is the targeting rule under RE. The rule (23) shows that only the Lagrange multiplier associated with the evolution of inflation expectations, i.e. $\lambda_{3, t}$, plays a role in the setting of optimal monetary policy. It follows from (23) that 


$$
\lambda_{3, t}=-\frac{1}{\gamma}\left(\pi_{t}+\frac{\alpha}{\kappa} x_{t}\right)
$$

The Lagrange multiplier $\lambda_{3, t}$ here represents, according to Molnár and Santoro (2014), the marginal effect of an increase in inflation expectations on welfare loss at time $t+1$. The learning hypothesis means that $\gamma>0$, and hence the sign of $\lambda_{3, t}$ depends on whether inflation expectations formed in the current period $a_{t}$ are positive or not. Indeed, since inflation target is set to zero, $a_{t}$ could be either positive or negative depending on the nature of past shocks. If $a_{t}$ is positive (negative), an increase in $a_{t}$ drives future inflation expectations further away from (closer to) the target and hence reduces (increases) the social welfare, implying that $\lambda_{3, t}$ is positive (negative).

Combining equations (18) and (20) leads to

$$
x_{t}=-\frac{\kappa \theta}{\alpha} h_{t}
$$

Substituting $h_{t}$ by its value given by (25) into (1) yields a modified Phillips curve:

$$
\pi_{t}=\beta E_{t}^{*} \pi_{t+1}+\left(\kappa-\frac{\alpha}{\kappa \theta}\right) x_{t}+e_{t}
$$

where the response of inflation to a change in the output gap decreases with increased concern of the CB for robustness (i.e. a decrease in $\theta$ ).

The second-order condition for the malevolent agent's maximization problem, i.e. $\frac{\partial^{2} \mathscr{L}_{t}^{C B}}{\partial^{2} h_{t}}<0$, implies $\theta>$ $\frac{\alpha}{\alpha+\kappa^{2}} \cdot{ }^{14}$ To ensure that the sign for the coefficients of the ALMs under learning will not be counterfactual, we impose a lower bound on $\theta$, i.e. ${ }^{15}$

$$
\theta>\frac{\alpha}{\kappa^{2}}
$$

which is more restrictive than the corresponding one imposed under RE, i.e. $\theta>\frac{\alpha}{\alpha+\kappa^{2}}$. The model has a unique solution corresponding to the CB's min-max problem under constant-gain learning (Appendices A.1 and A.2).

The ALM for inflation is

$$
\pi_{t}=c_{\pi}^{c g} a_{t}+d_{\pi}^{c g} e_{t}
$$

where $c_{\pi}^{c g}=-\frac{p_{0}+p_{2}\left(c_{\pi}^{c g}\right)^{2}}{p_{1}} \equiv f\left(c_{\pi}^{c g}\right), d_{\pi}^{c g}=\frac{\alpha \theta}{\theta\left(\alpha+\kappa^{2}\right)-\alpha+\theta \alpha \gamma^{2} \beta^{2}\left(\beta-c_{\pi}^{c g}\right)+\gamma \beta(1-\gamma)\left[\theta \alpha \beta-\left(\theta\left(\alpha+\kappa^{2}\right)-\alpha\right) c_{\pi}^{c g}\right]}$, with $p_{0}=$ $\alpha \beta \theta\{1-\beta(1-\gamma)[1-\gamma(1-\beta)]\}>0, p_{2}=\gamma \beta\left\{\left(\kappa^{2} \theta-\alpha\right)(1-\gamma)+\theta \alpha[1-\gamma(1-\beta)]\right\}, p_{1}=-\left(\kappa^{2} \theta-\right.$ $\alpha)[1-\beta(1-\gamma)]-\alpha \theta(1-\beta)\{1-\beta[1-\gamma(1-\beta)])\}-p_{0}-p_{2}$.

Under the condition $\theta>\frac{\alpha}{\kappa^{2}}$, we have $p_{2}>0$ and $p_{1}<0$. The solution for $c_{\pi}^{c g}$ that ensures a non-explosive evolution of $\pi_{t}$ described by the ALM for inflation (28) is:

$$
c_{\pi}^{c g}=\frac{-p_{1}-\sqrt{p_{1}^{2}-4 p_{2} p_{0}}}{2 p_{2}}
$$

where $0<c_{\pi}^{c g}<\frac{\alpha \beta \theta}{\theta\left(\alpha+\kappa^{2}\right)-\alpha}$ (Appendix A.2). The last condition implies $c_{\pi}^{c g}<\beta$ and $d_{\pi}^{c g}<1$. When expectations are constant, i.e. $\gamma=0$, we obtain $c_{\pi}^{c g}=\frac{\alpha \beta \theta}{\theta\left(\alpha+\kappa^{2}\right)-\alpha}$, and $d_{\pi}^{c g}=\frac{\alpha \theta}{\theta\left(\alpha+\kappa^{2}\right)-\alpha}$.

Inserting $\pi_{t}$ given by (28) and $h_{t}=-\frac{\alpha}{\kappa \theta} x_{t}$ obtained from (25) into (1), we obtain the ALM for the output gap:

$$
x_{t}=c_{x}^{c g} a_{t}+d_{x}^{c g} e_{t}
$$

where $c_{x}^{c g}=-\frac{\kappa \theta}{\kappa^{2} \theta-\alpha}\left(\beta-c_{\pi}^{c g}\right)<0$ and $d_{x}^{c g}=-\frac{\kappa \theta}{\kappa^{2} \theta-\alpha}\left(1-d_{\pi}^{c g}\right)<0$. Given that $c_{\pi}^{c g}<\beta$ and $d_{\pi}^{c g}<1,(27)$ ensures that $c_{x}^{c g}<0$ and $d_{x}^{c g}<0$ so that they are consistent with empirical findings. Substituting $x_{t}$ given by (30) in (3) yields the ALM for the interest rate: 


$$
r_{t}=\delta_{r}^{c g} b_{t}+c_{r}^{c g} a_{t}+d_{r}^{c g} e_{t}
$$

where $\delta_{r}^{c g}=\sigma, c_{r}^{c g}=1+\frac{\sigma \kappa \theta}{\kappa^{2} \theta-\alpha}\left(\beta-c_{\pi}^{c g}\right)$ and $d_{r}^{c g}=\frac{\sigma \kappa \theta}{\kappa^{2} \theta-\alpha}\left(1-d_{\pi}^{c g}\right)$. In the ALM for the interest rate, the output-gap expectations have constant feedback effects, no matter how robust the policy is.

The feedback effects of inflation expectations and cost-push shocks on inflation, the output gap and the interest rate are function of the preference for robustness. It is to notice that the ALMs for inflation and the output gap are independent of output-gap expectations under both learning and RE, while the interest rate under learning responds to output-gap expectations with the same coefficient as under RE.

Notice that for $\gamma=0$, the feedback coefficients in the ALMs are identical to those in (9)-(11), hence identical to those under RE. Indeed, in the absence of learning, inflation and output-gap expectations remain anchored at their steady-state values and thus are identical to those obtained under RE (Appendix A.2).

\section{Robustness and the effects of constant-gain learning}

The comparison of equilibria under learning and under the RE hypothesis is done exhaustively in Molnár and Santoro (2014), so we focus on the difference induced by constant-gain learning and robustness compared to the benchmark model without model uncertainty.

\subsection{The stability condition}

The existence of a converging solution for $c_{\pi}^{c g}$ ensures that there is a converging solution for other coefficients of ALMs, such as $c_{x}^{c g}, d_{\pi}^{c g}, d_{x}^{c g}, c_{r}^{c g}$, and $d_{r}^{c g}$ while $\delta_{r}^{c g}$ is independent of learning and robust control. Comparing the existence condition of a converging path for inflation under RE and the one obtained under learning leads to the following proposition.

\section{Proposition 1: Adaptive learning imposes a more restrictive constraint on monetary policy robustness}

The CB can ensure the dynamic stability of the economy by imposing a higher lower bound on the parameter representing its preference for robustness when private agents form expectations under constant-gain learning, i.e. $\theta>\frac{\alpha}{\kappa^{2}}$, than under rational expectations, i.e. $\theta>\frac{\alpha}{\alpha(1-\beta)+\kappa^{2}}$.

\section{Proof.}

See Appendix A.2.

A higher lower bound for $\theta$ implies a smaller possibility for the CB to implement a robust monetary policy strategy. To show the difference between the thresholds imposed on the CB's preference for robustness under learning and RE, we use Woodford's (1999) parameter values, $\alpha=0.048, \beta=0.99$ and $\kappa=0.024$, and find that under adaptive learning, the threshold for $\theta$ above which the dynamic system is stable is 83.33. Meanwhile, for the same parameter values, the corresponding threshold for $\theta$ under RE is 45.45 . This indicates that the CB should have much less fear for model misspecifications when private agents are learning than under RE. One possible explanation of this difference is that learning is one kind of model misspecification so that to deal with the fact that private agents are learning, the CB should have less concern for model misspecification regarding the Phillips curve. Notice that the value of $\theta$ compatible with the dynamic stability of the equilibrium is smaller than the lower bound on $\theta$, i.e. $\theta>\frac{\alpha}{\kappa^{2}}$, imposed to ensure that the sign of the coefficients in the ALMs under learning is not counterfactual. Consequently, the condition ensuring the dynamic stability is $\theta>\frac{\alpha}{\kappa^{2}}$. This implies that the threshold ensuring the dynamic stability of the equilibrium under learning is independent of the learning coefficient.

\subsection{The effects of robustness on the feedback coefficients of ALMs}

To the difference of Molnár and Santoro (2014), the effects of learning interact with the CB's preference for robustness in the present model. We evaluate here how the conduct of monetary policy is affected by learning and model robustness.

Deriving $c_{\pi}^{c g}, d_{\pi}^{c g}, c_{x}^{c g}, d_{x}^{c g}, c_{r}^{c g}$, and $d_{r}^{c g}$ with respect to $\gamma$ and examining their sign lead to the following proposition. 


\section{Proposition 2: Adaptive learning makes robust monetary policy less accommodative compared to RE}

An increase in the learning gain $\gamma$ reduces (increases) the feedback coefficients of inflation expectations and cost-push shocks in the ALMs for inflation and the output gap (the nominal interest rate) compared to those obtained under RE.

\section{Proof.}

See Appendix A.3.

Comparing (9)-(11) with (28), (30) and (31), we find that the feedback effect of inflation expectations on the ALM for inflation (the output gap) is attenuated (amplified) under learning compared to RE, i.e. $c_{\pi}^{c g}<\frac{\alpha \beta \theta}{\theta\left(\alpha+\kappa^{2}\right)-\alpha}$ $\left(c_{x}^{c g}<\frac{-\beta \kappa \theta}{\theta\left(\alpha+\kappa^{2}\right)-\alpha}\right.$, respectively) and this is made possible by the stronger response of the interest rate to inflation expectations under learning, i.e. $c_{r}^{c g}>1+\frac{\kappa \theta \sigma}{\kappa^{2} \theta-\alpha}$. The interest rate reacts more strongly as $\gamma$ increases. Regarding the feedback coefficients associated with cost-push shocks in the ALMs, it is straightforward to show that $d_{\pi}^{c g}<$ $\frac{\alpha \theta}{\theta\left(\alpha+\kappa^{2}\right)-\alpha}, d_{x}^{c g}<-\frac{\kappa \theta}{\theta\left(\alpha+\kappa^{2}\right)-\alpha}$ and $d_{r}^{c g}>\frac{\sigma \kappa \theta}{\theta\left(\alpha+\kappa^{2}\right)-\alpha}$, meaning that under learning, inflation is less sensitive while the output gap and the interest rate are more sensitive to current cost-push shocks than under RE.

Using the baseline parameter values, $\alpha=0.048, \beta=0.99$, and $\kappa=0.024$ and $\sigma=0.157$, Figure 1 shows how the learning gain $\gamma$ and the preference for model robustness $\theta$ affect the feedback coefficients in the ALMs.

It emerges from Figure 1 that the learning process with a non-trivial learning gain (i.e. $\gamma>0$ ) attenuates the feedback effects in the ALMs for inflation but amplifies these effects in the ALM for the output gap and the interest rate compared to the corresponding ones under RE (which are identical to the ones with $\gamma=0$ ). More precisely, both feedback coefficients $c_{\pi}^{c g}$ and $d_{\pi}^{c g}$ are positive and smaller than unit and decrease with $\gamma$. Comparing the effect of an increase in $\gamma$ on $c_{\pi}^{c g}$ and $d_{\pi}^{c g}$, we find that $c_{\pi}^{c g}$ decreases at a much faster rate than $d_{\pi}^{c g}$. We notice that as $\gamma$ reaches 0.2 , the value of $c_{\pi}^{c g}$ is very close to the one obtained with $\gamma=1$ while the value of $d_{\pi}^{c g}$ is quite far away from its value for $\gamma=1$. Similar observation could be made with $d_{\pi}^{c g}, d_{x}^{c g}, c_{r}^{c g}$, and $d_{r}^{c g}$.
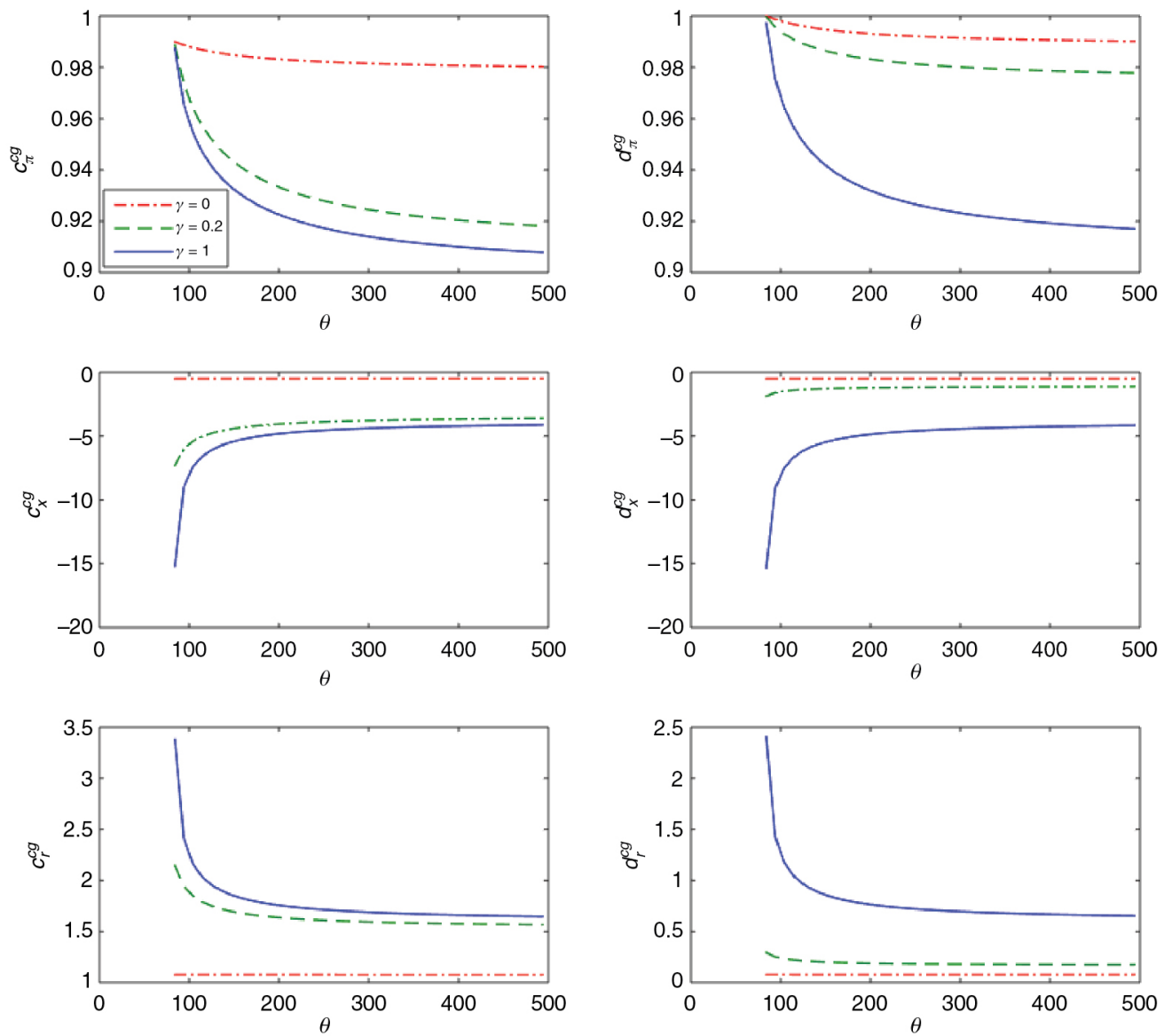

Figure 1: The feedback coefficients of the ALMS.

Using (9)-(11), it is easy to show that under RE, the absolute value of the coefficients in the ALMs are all increasing as $\theta$ decreases, meaning that an increase in the CB's preference for model robustness amplifies the responses of all endogenous variables to a change in expected inflation and cost-push shocks. Given that 
the inflation target is equal to zero, the expected inflation at the REE is always equal to zero and the effect of robustness on the economy is transmitted through the coefficients associated with cost-push shocks in (9)-(11).

Using the baseline parameter values, Figure 2 illustrates how the partial derivatives with respect to $\theta$ of the feedback coefficients in the ALMs evolve with the learning gain $\gamma$ and the preference for model robustness $\theta$.
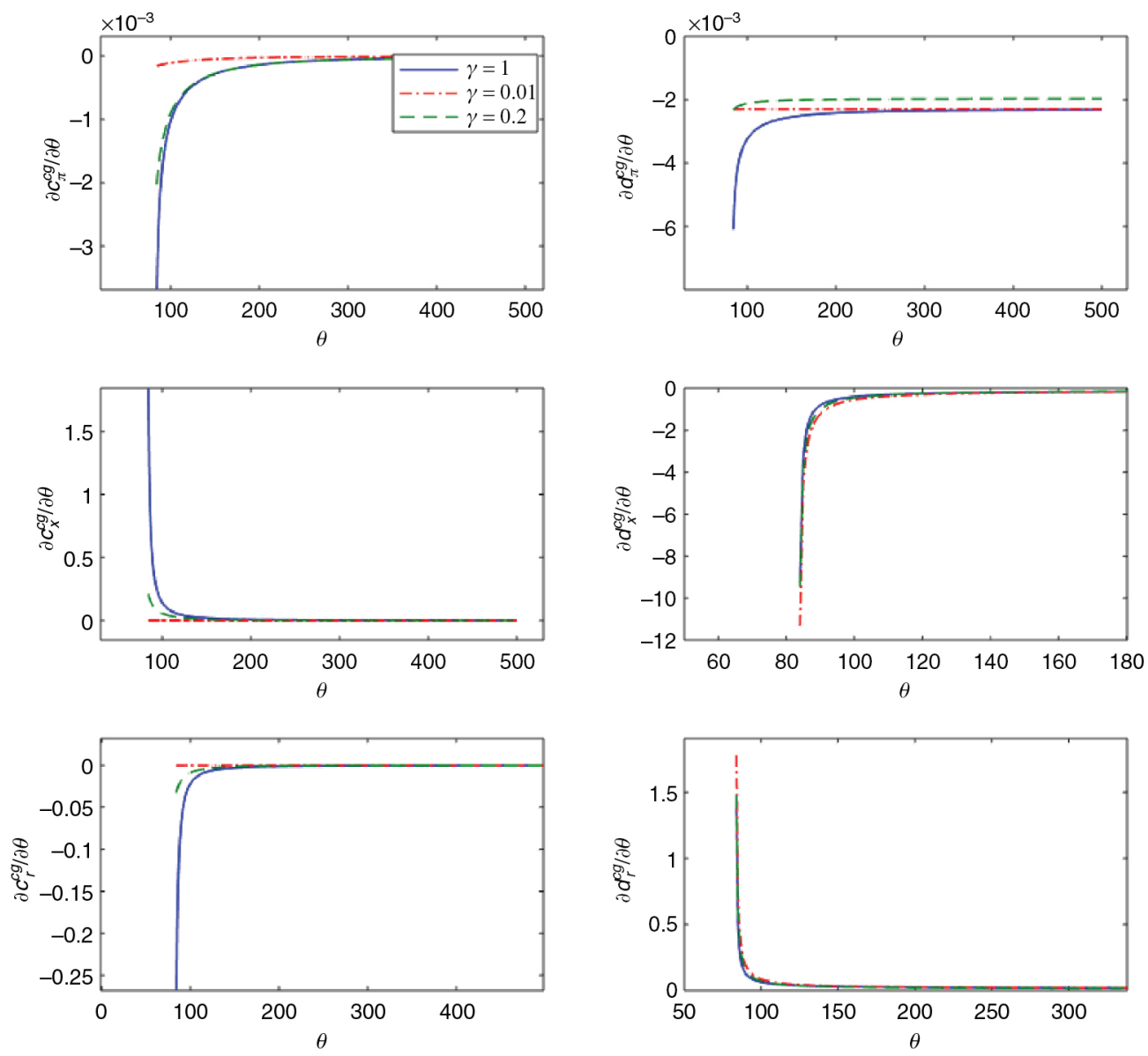

Figure 2: The sensitiveness of partial derivatives for $\theta$ of the feedback coefficients in the ALMs to $\gamma$ and $\theta$.

Deriving the feedback coefficients in (28), (30) and (31) with respect to $\theta$ yields the following proposition.

\section{Proposition 3: Cautiousness of robust monetary policy under adaptive learning}

An increase in the CB's preference for model robustness (i.e. lower $\theta$ ) dampens (amplifies) the response of inflation (the output gap and the nominal interest rate) to inflation expectations and cost-push shocks. The response of the nominal interest rate to output-gap expectations is independent of model robustness, i.e. $\frac{\partial \delta_{r}^{c g}}{\partial \theta}=0$. Adaptive learning strengthens the aggressive response of the $C B$ to cost-push shocks or a change in inflation expectations compared to those observed under rational expectations.

\section{Proof.}

See Appendix A.4.

Fearing the worst-case scenarios, the CB becomes more aggressive in its responses to cost-push shocks and a change in inflation expectations under RE (Leitemo and Söderström 2008). This effect is also present when private agents form expectations using a learning algorithm and comes to reinforce the attenuation (reinforce the amplification) effects of learning on the feedback coefficients in the ALM for inflation (the output gap and the interest rate). In other words, adaptive learning makes the central bank more cautious in the sense of Giannoni (2007) and Söderström (2002) but less cautious in the sense of Brainard (1967) and leads the CB to conduct a more aggressive interest rate policy that dampens (amplifies) the effects of a change in inflation expectations and cost-push shocks on inflation (the output gap).

For the baseline parameter values, Figure 3 illustrates how the partial derivatives with respect to $\gamma$ of the feedback coefficients in the ALMs evolve with the learning gain $\gamma$ and the preference for model robustness $\theta$.

It follows from Figure 3 that a decrease in $\theta$ increases $\frac{\partial c_{\pi}^{c g}}{\partial \gamma}, \frac{\partial d_{\pi}^{c g}}{\partial \gamma}, \frac{\partial c_{r}^{c g}}{\partial \gamma}$ and $\frac{\partial d_{r}^{c g}}{\partial \gamma}$ but reduces $\frac{\partial c_{x}^{c g}}{\partial \gamma}$ and $\frac{\partial d_{x}^{c g}}{\partial \gamma}$. We notice that the marginal effect of a decrease in $\theta$ on the marginal effect of $\gamma$ is quite insensitive to the value of $\gamma$ in the case of $c_{x}^{c g}, d_{x}^{c g}, c_{r}^{c g}$, and $d_{r}^{c g}$. The numerical simulation leads to the following proposition. 


\section{Proposition 4:}

For standard parameter values, an increase in the CB's preference for robustness (i.e. a decrease in $\theta$ ) increases the marginal effects of learning gain on the feedback coefficients in the ALMs for inflation and the nominal interest rate but decreases those on the feedback coefficients in the ALM for the output gap.
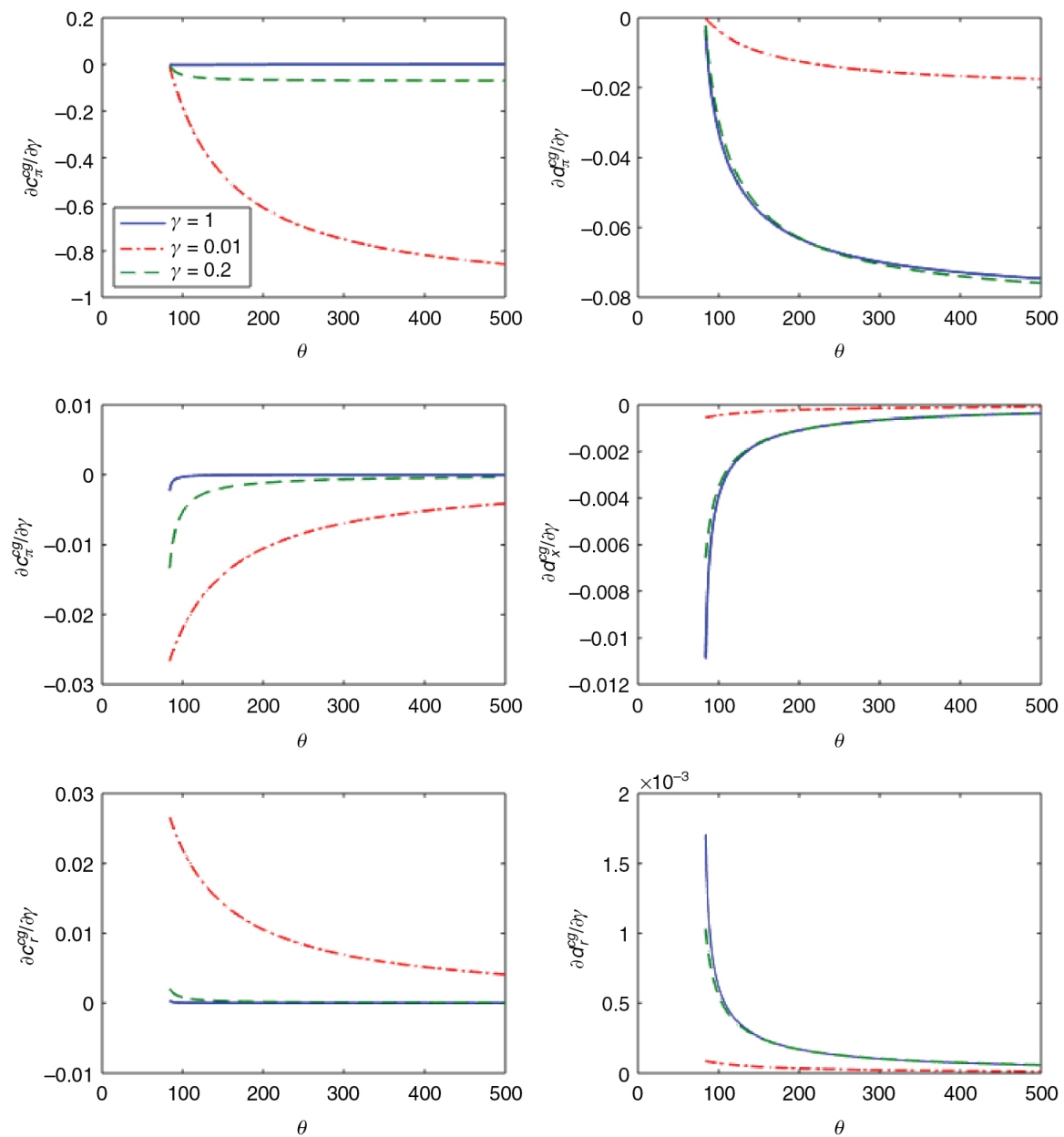

Figure 3: The sensitiveness of partial derivatives for $\gamma$ of the feedback coefficients in the ALMs to $\gamma$ and $\theta$.

\section{Discussions}

The finding that constant-gain adaptive learning strengthens the argument in favor of a more aggressive robust monetary policy is obtained in a standard New Keynesian model with the central bank being confronted to additive model misspecifications. The policy implications of this paper are however subject to several limitations of the model. The most important among them are the assumption that the learning gain is time invariant, the additive nature of model misspecifications, the absence of the zero lower bound, and the negligence of the interactions between monetary policy and financial frictions. Eliminating some of these limitations may give rise to promising extensions.

First, the assumption of constant-gain learning can be relaxed. It can be substituted by various learning behaviors investigated in the literature ${ }^{16}$ One immediate extension to our model is to consider that private agents use a decreasing-gain algorithm as in Molnár and Santoro (2014) and André and Dai (2017), and examine how the robust control approach could affect the effect of decreasing-gain learning on optimal monetary policy. ${ }^{17}$ We can state with confidence that since the learning gain decreases with time, the temporary equilibria under decreasing-gain learning replicate more or less those under constant-gain learning with given learning gains. However, it will be more difficult to find an analytical solution as the evolution of learning gain affects the current equilibrium and induces complex interactions between learning and model misspecifications. Furthermore, the robustness of our results could be checked by considering alternative learning algorithms such as least squares learning and Bayesian learning. 
Second, the robust control approach in this paper only deals with additive model misspecification. An idea popularized by Brainard (1967) and emphasized by Blinder (1998) and others is that policymakers should be cautious by "doing less" when facing to uncertainty about the true parameters of a model. An alternative approach to robustness is to consider multiplicative Knightian uncertainty by assuming that the uncertainty is located in one or more specific parameters of the model, and the true values of these parameters are known only to be bounded between minimum and maximum plausible values (Giannoni 2002; 2007; Onatski and Stock 2002; Tetlow and von zur Muehlen 2004). However, implementing multiplicative uncertainty makes it impossible to obtain any analytical result (Söderström 2002). Numerical simulations show that in the presence of parameter uncertainty, the robust monetary policy rule implies that the interest rate generally reacts more strongly to changes in inflation and the output gap, with greater inertia than in the absence of such uncertainty. The policymaker is less cautious than in Brainard's model, as he cares very much about worst-case situations. Multiplicative uncertainty makes it more difficult for private agents to forecast the future and hence provides a stronger argument for their learning behavior. It would be worthwhile to see how adding multiplicative uncertainty to a model with adaptive learning changes the results obtained when model misspecification is additive.

Recent global financial crisis has attracted a great attention to the role played by financial intermediation and frictions in the monetary transmission mechanism. A number of studies introduce financial frictions in New Keynesian models. ${ }^{18}$ Such frictions tend to amplify the fluctuations in inflation and the output gap, especially when private agents adopt learning behaviors, implying that monetary policy must be more aggressive in response to inflation shocks than under RE (Caputo, Medina, and Soto 2011; Rychalovska, Slobodyan, and Wouters 2015; Hollmayr and Kühl 2016). These results suggest that the interactions between learning and robust monetary policy in the presence of financial frictions could be quite different from those in the absence of such frictions.

Another current hot topic is to assess whether learning is able or not to avoid convergence to a liquidity trap since large shocks can put economic variables on an unstable path leading to the zero lower bound (ZLB) regime (Honkapohja 2016). Incorporating forward guidance into the learning approach, Honkapohja and Mitra (2015) show that both price level and nominal GDP targeting can better help avoiding an expectations-driven liquidity trap than under inflation targeting. The effectiveness of these two policy regimes when private agents are learning largely depends on the credibility of monetary policy that is measured by the degree with which forward guidance about the future path of the target variable is integrated into the learning process. These issues deserve further examination in a framework where the central bank sets optimal robust monetary policy.

\section{Conclusion}

This paper explores the implications for macroeconomic stabilization when both adaptive learning and concern for additive model misspecification are present. It is shown that the fact that private agents form expectations using learning algorithm substantially reduces the set of possible model misspecifications compatible with the dynamic stability of the economy, compared to the possible set under rational expectations. Regarding the effects of robustness, we find that the results obtained by Leitemo and Söderström (2008) under rational expectations hypothesis, i.e. the robust monetary policy becomes more aggressive, are still valid. Moreover, due to adaptive learning, the optimal robust monetary policy becomes even more aggressive than under rational expectations. The response of inflation (the output gap and the nominal interest rate) to cost-push shocks and to a change in inflation expectations under adaptive learning is dampened (amplified) by an increase of the central bank's preference for model robustness.

\section{Acknowledgement}

We are grateful to Jean-Bernard Chatelain, Francesco De Palma, Amélie Barbier-Gauchard, Rodolphe Dos Santos Ferreira, Moïse Sidiropoulos, Marco Maria Sorge and an anonymous reviewer for helpful remarks and suggestions.

\section{A Appendix}

In subsections A.1 and A.2, we closely follow Molnár and Santoro (2014) to find the equilibrium solution under learning. In subsections A.3 and A.4, we develop original techniques to show the effects of learning and robustness on the equilibrium. 


\section{A.1 The equilibrium solution of inflation under learning}

Substituting $\lambda_{2, t+1}=0, \lambda_{3, t}$ and $\lambda_{3, t+1}$ given by (24) and $\lambda_{1, t+1}=-\frac{\alpha}{\kappa} x_{t+1}$ from (20) into (21), we obtain

$$
\pi_{t}=-\frac{\alpha}{\mathcal{K}} x_{t}+\beta(1-\gamma) E_{t}^{*} \pi_{t+1}+\left[\frac{\alpha \gamma \beta^{2}}{\mathcal{\kappa}}+\beta(1-\gamma) \frac{\alpha}{\mathcal{\kappa}}\right] E_{t}^{*} x_{t+1} .
$$

Using $E_{t} \pi_{t+1} \equiv a_{t}$ and (26), we get:

$$
\begin{gathered}
x_{t}=\frac{\kappa \theta}{\kappa^{2} \theta-\alpha}\left(\pi_{t}-\beta a_{t}-e_{t}\right), \\
x_{t+1}=\frac{\kappa \theta}{\kappa^{2} \theta-\alpha}\left(\pi_{t+1}-\beta a_{t+1}-e_{t+1}\right) .
\end{gathered}
$$

Substituting $x_{t}$ and $x_{t+1}$ given by (33)-(34) into (32) and arranging the terms yields:

$$
E_{t}^{*} \pi_{t+1}=A_{11} \pi_{t}+A_{12} a_{t}+P_{1} e_{t}
$$

with

$$
\begin{gathered}
A_{11} \equiv \frac{\kappa^{2} \theta-\alpha+\alpha \theta+\theta \alpha \gamma \beta^{2}[1-\gamma(1-\beta)]}{\beta\left\{\left(\kappa^{2} \theta-\alpha\right)(1-\gamma)+\theta \alpha[1-\gamma(1-\beta)]\right\}}, \\
A_{12} \equiv-\frac{\alpha \beta \theta[1-\beta(1-\gamma)[1-\gamma(1-\beta)]]}{\beta\left\{\left(\kappa^{2} \theta-\alpha\right)(1-\gamma)+\theta \alpha[1-\gamma(1-\beta)]\right\}}, \\
P_{1} \equiv-\frac{\alpha \theta}{\beta\left\{\left(\kappa^{2} \theta-\alpha\right)(1-\gamma)+\theta \alpha[1-\gamma(1-\beta)]\right\}} .
\end{gathered}
$$

According to the proposition 1 from Blanchard and Kahn (1980), the ALM solution for inflation takes the following form :

$$
\pi_{t}=c_{\pi}^{c g} a_{t}+d_{\pi}^{c g} e_{t} .
$$

Advancing (39) one period and taking the expectation of the resulting equation while using (6) yield:

$$
E_{t}^{*} \pi_{t+1}=c_{\pi}^{c g}\left[(1-\gamma) a_{t}+\gamma \pi_{t}\right] .
$$

Using (35) to eliminate $E_{t} \pi_{t+1}$ in (40) and arranging the terms, we get:

$$
\pi_{t}=\frac{A_{12}-c_{\pi}^{c g}(1-\gamma)}{c_{\pi}^{c g} \gamma-A_{11}} a_{t}+\frac{P_{1}}{c_{\pi}^{c g} \gamma-A_{11}} e_{t}
$$

Comparing (39) and (41) yields:

$$
c_{\pi, t}^{c g}=\frac{A_{12}-c_{\pi}^{c g}(1-\gamma)}{c_{\pi}^{c g} \gamma-A_{11}},
$$

and

$$
d_{\pi, t}^{c g}=\frac{P_{1}}{c_{\pi}^{c g} \gamma-A_{11}}
$$


We gather equations (6), (7) and (35), while using (33) to substitute $x_{t}$ to obtain the system of three equations:

$$
E_{t}^{*} y_{t+1}=A_{t} y_{t}+P_{t} e_{t}
$$

where

$$
y_{t} \equiv\left[\begin{array}{lll}
\pi_{t} & a_{t} & b_{t}
\end{array}\right], A \equiv\left[\begin{array}{ccc}
A_{11} & A_{12} & 0 \\
\gamma & 1-\gamma & 0 \\
-\frac{\kappa \theta \gamma}{\alpha-\kappa^{2} \theta} & \frac{\gamma \beta \kappa \theta}{\alpha-\kappa^{2} \theta} & 1-\gamma
\end{array}\right] \text {, and } P \equiv\left[\begin{array}{c}
P_{1} \\
0 \\
\kappa \theta \gamma \\
\frac{\alpha-\kappa^{2} \theta}{\alpha}
\end{array}\right] \text {. }
$$

The above system is subject to three boundary conditions: $a_{0}, b_{0}$, and $\lim _{s \rightarrow \infty}\left|E_{t}^{*} \pi_{t+s}\right|<\infty$. The eigenvalues of $A_{t}$ are $1-\gamma$ and the two eigenvalues of $A_{1}$ :

$$
A_{1}=\left[\begin{array}{cc}
A_{11} & A_{12} \\
\gamma & 1-\gamma
\end{array}\right]
$$

We can show that, in Appendix A.2, $A_{1}$ has an eigenvalue inside and one outside the unit circle. $\square$

\section{A.2 The single stable solution}

Among infinite stochastic sequences satisfying equation (42), we focus on a non-explosive solution, i.e. the solution corresponding to the eigenvalue of $A_{1}$ given by (44) inside the unit circle. The trace and determinant of $A_{1}$ are both positive. Thus, for $A_{1}$ to have two real eigenvalues $\left(\mu_{1}, \mu_{2}\right)$, one inside and one outside the unit circle, it is sufficient to show that $\left(1-\mu_{1}\right)\left(1-\mu_{2}\right)<0$. This can be rewritten as:

$$
\mu_{1}+\mu_{2}>1+\mu_{1} \mu_{2} .
$$

Knowing that $\mu_{1}+\mu_{2}$ is equal to the trace of $A_{1}$ and $\mu_{1} \mu_{2}$ equal to its determinant, we rewrite (45) as:

$$
\begin{aligned}
\frac{\kappa^{2} \theta-\alpha+\alpha \theta+\theta \alpha \gamma \beta^{2}[1-\gamma(1-\beta)]}{\beta\left\{\left(\kappa^{2} \theta-\alpha\right)(1-\gamma)+\theta \alpha[1-\gamma(1-\beta)]\right\}}+1-\gamma>1+(1-\gamma) \frac{\kappa^{2} \theta-\alpha+\alpha \theta+\theta \alpha \gamma \beta^{2}[1-\gamma(1-\beta)]}{\left.\beta\left\{\kappa^{2} \theta-\alpha\right)(1-\gamma)+\theta \alpha[1-\gamma(1-\beta)]\right\}} \\
+\gamma \frac{\alpha \beta \theta[1-\beta(1-\gamma)[1-\gamma(1-\beta)]]}{\beta\left\{\left(\kappa^{2} \theta-\alpha\right)(1-\gamma)+\theta \alpha[1-\gamma(1-\beta)]\right\}} .
\end{aligned}
$$

After simplification, we get:

$$
\left(\kappa^{2} \theta-\alpha\right)[1-\beta(1-\gamma)]+\alpha \theta(1-\beta)\{1-\beta[1-\gamma(1-\beta)]\}>0,
$$

which is verified given that $\beta \in] 0,1[$ and $\gamma \in[0,1]$ and condition (27).

There exists a unique solution to the model, whose ALM takes the following form:

$$
\pi_{t}=c_{\pi}^{c g} a_{t}+d_{\pi}^{c g} e_{t} .
$$

To have a converging (and non-explosive) inflation, we must have $c_{\pi}^{c g} \in[0,1]$. Rewriting $(42)$ as $\gamma\left(c_{\pi}^{c g}\right)^{2}-A_{11} c_{\pi}^{c g}-$ $A_{12}+c_{\pi}^{c g}(1-\gamma)=0$ and substituting $A_{11}$ and $A_{12}$ by their expressions, we obtain:

$$
p_{2}\left(c_{\pi}^{c g}\right)^{2}+p_{1} c_{\pi}^{c g}+p_{0}=0
$$

where

$$
\begin{aligned}
& p_{0}=\alpha \beta \theta\{1-\beta(1-\gamma)[1-\gamma(1-\beta)]\}>0 \\
& p_{2}=\gamma \beta\left\{\left(\kappa^{2} \theta-\alpha\right)(1-\gamma)+\alpha \theta[1-\gamma(1-\beta)]\right\} \\
& p_{1}=\alpha+\beta(1-\gamma)\left\{\left(\kappa^{2} \theta-\alpha\right)(1-\gamma)+\alpha \theta[1-\gamma(1-\beta)]\right\}-\left\{\theta\left(\kappa^{2}+\alpha\right)+\alpha \beta^{2} \gamma \theta[1-\gamma(1-\beta)]\right\} .
\end{aligned}
$$


To characterize the two solutions of $c_{\pi}^{c g}$, we rewrite (47) as:

$$
c_{\pi}^{c g}=-\frac{p_{0}+p_{2}\left(c_{\pi}^{c g}\right)^{2}}{p_{1}} \equiv f\left(c_{\pi}^{c g}\right) .
$$

We rewrite $p_{1}$, after some tedious calculus, as

$$
\left.p_{1}=-\left(\kappa^{2} \theta-\alpha\right)[1-\beta(1-\gamma)]-\alpha \theta(1-\beta)\{1-\beta[1-\gamma(1-\beta)])\right\}-p_{0}-p_{2},
$$

or alternatively simplify it as

$$
p_{1}=-\beta p_{2}-\frac{\theta\left(\alpha+\kappa^{2}\right)-\alpha}{\theta \alpha \beta} p_{0} .
$$

The conditions imposed on $\theta$ to ensure that $p_{2}>0$, i.e. $\theta>\frac{\alpha}{\alpha\left(1+\frac{\gamma \beta}{1-\gamma}\right)+\kappa^{2}}$, and that $p_{1}<0$, i.e. $\theta>\frac{\alpha}{\kappa^{2}+\alpha\left(1+\frac{\gamma^{2} \beta^{3}}{1-\beta(1-\gamma)^{2}}\right)^{\prime}}$, are less restrictive than condition (27), i.e. $\theta>\frac{\alpha}{\kappa^{2}}$ that is imposed to ensure that current output gap decreases with a rise in expected inflation or a positive cost-push shocks.

Under RE, to ensure the dynamic stability of the equilibrium, we must have according to (9) that $\frac{\alpha \theta \beta}{\theta\left(\alpha+\kappa^{2}\right)-\alpha}<$ 1 , or equivalently $\theta>\frac{\alpha}{\alpha(1-\beta)+\kappa^{2}}$, which is more restrictive than the condition (12), i.e. $\theta>\frac{\alpha}{\alpha+\kappa^{2}}$. Thus, the stability condition is $\theta>\frac{\alpha}{\alpha(1-\beta)+\kappa^{2}}$.

For $\theta>\frac{\alpha}{\kappa^{2}}$, we always have $p_{2}>0$, and $p_{1}<0$. This implies that $f\left(c_{\pi}^{c g}\right):[0,1] \rightarrow[0,1]$, with $f(0)=$ $-\frac{p_{0}+p_{2}}{p_{1}}>0$ and $0<f(1)=\frac{p_{0}+p_{2}}{p_{1}}<1$ and $f^{\prime}\left(c_{\pi}^{c g}\right)=-\frac{2 p_{2}}{p_{1}} c_{\pi}^{c g}>0$. Hence, the Brower theorem and the fact that $f\left(c_{\pi}^{c g}\right)$ is strictly monotonously increasing in the interval $c_{\pi}^{c g} \in[0,1]$ imply that there is a unique solution in this interval. The other possible solution is greater than unit and is excluded because it leads to an explosive evolution of inflation.

To ensure that $-p_{1}>p_{0}+p_{2}$ and hence the existence of a stable solution, we must have $\left(\kappa^{2} \theta-\right.$ a) $[1-\beta(1-\gamma)]+\alpha \theta(1-\beta)\{1-\beta[1-\gamma(1-\beta)])\}>0$. This implies that:

$$
\theta>\frac{\alpha}{\alpha(1-\beta)\left[1-\frac{\gamma \beta^{2}}{1-\beta(1-\gamma)}\right]+\kappa^{2}} .
$$

The stability condition given by (51) is too loose compared to condition (27), i.e. $\theta>\frac{\alpha}{\kappa^{2}}$. As a result, the stability condition is $\theta>\frac{\alpha}{\kappa^{2}}$ instead of (51).

The stable solution of $c_{\pi}^{c g}$ is given by

$$
c_{\pi}^{c g}=\frac{-p_{1}-\sqrt{p_{1}^{2}-4 p_{2} p_{0}}}{2 p_{2}} .
$$

The other possible solution $c_{\pi}^{c g}=\frac{-p_{1}+\sqrt{p_{1}^{2}-4 p_{2} p_{0}}}{2 p_{2}}$ is greater than unit and is excluded to avoid an explosive evolution of inflation. Substituting $A_{11}$ and $P_{1}$ into (43) and rearranging the terms leads to:

$$
d_{\pi}^{c g}=\frac{\alpha \theta}{\theta\left(\alpha+\kappa^{2}\right)-\alpha+\theta \alpha \gamma^{2} \beta^{2}\left(\beta-c_{\pi}^{c g}\right)+\gamma \beta(1-\gamma)\left\{\theta \alpha \beta-\left[\theta\left(\alpha+\kappa^{2}\right)-\alpha\right] c_{\pi}^{c g}\right\}} .
$$

We now show that $f\left(c_{\pi}^{c g}\right)$ defined in (48) is bounded, i.e. $\left.f\left(c_{\pi}^{c g}\right):\left[0 ; \frac{\alpha \beta \theta}{\theta\left(\alpha+\kappa^{2}\right)-\alpha}\right] \rightarrow\right] 0 ; \frac{\alpha \beta \theta}{\theta\left(\alpha+\kappa^{2}\right)-\alpha}[$. Knowing that $f(0)>0$ and substituting $c_{\pi}^{c g}$ by $\frac{\alpha \beta \theta}{\theta\left(\alpha+\kappa^{2}\right)-\alpha}$ into the function $f\left(c_{\pi}^{c g}\right)$, we find

$$
\begin{aligned}
f\left(\frac{\alpha \beta \theta}{\theta\left(\alpha+\kappa^{2}\right)-\alpha}\right) & =-\frac{p_{0}+p_{2}\left[\frac{\alpha \beta \theta}{\theta\left(\alpha+\kappa^{2}\right)-\alpha}\right]^{2}}{p_{1}} \\
& =\frac{\frac{\alpha \beta \theta}{\theta\left(\alpha+\kappa^{2}\right)-\alpha}\left\{\frac{\theta\left(\alpha+\kappa^{2}\right)-\alpha}{\alpha \beta \theta} p_{0}+\frac{\alpha \beta \theta}{\theta\left(\alpha+\kappa^{2}\right)-\alpha} p_{2}\right\}}{-p_{1}} .
\end{aligned}
$$


Using $p_{2}=\frac{\theta \alpha(1-\beta)+\kappa^{2} \theta-\alpha}{\theta \alpha+\kappa^{2} \theta-\alpha} p_{2}+\frac{\theta \alpha \beta}{\theta \alpha+\kappa^{2} \theta-\alpha} p_{2}, p_{0}=-\frac{\theta \alpha(1-\beta)+\kappa^{2} \theta-\alpha}{\theta \alpha \beta} p_{0}+\frac{\theta \alpha+\kappa^{2} \theta-\alpha}{\theta \alpha \beta} p_{0}$ and the definition of $p_{0}, p_{1}$, and $p_{2}$ given above, we substitute $p_{1}$ using (50), we obtain:

$$
\begin{aligned}
f\left(\frac{\alpha \beta \theta}{\theta\left(\alpha+\kappa^{2}\right)-\alpha}\right) & =-\frac{p_{0}+p_{2}\left[\frac{\alpha \beta \theta}{\theta\left(\alpha+\kappa^{2}\right)-\alpha}\right]^{2}}{p_{1}} \\
& =\frac{\frac{\alpha \beta \theta}{\theta\left(\alpha+\kappa^{2}\right)-\alpha}\left\{\frac{\theta\left(\alpha+\kappa^{2}\right)-\alpha}{\alpha \beta \theta} p_{0}+\frac{\alpha \beta \theta}{\theta\left(\alpha+\kappa^{2}\right)-\alpha} p_{2}\right\}}{\frac{\beta\left(\kappa^{2} \theta-\alpha\right)}{\theta\left(\alpha+\kappa^{2}\right)-\alpha} p_{2}+\frac{\theta\left(\alpha+\kappa^{2}\right)-\alpha}{\theta \alpha \beta} p_{0}+\frac{\theta \alpha \beta}{\theta\left(\alpha+\kappa^{2}\right)-\alpha} p_{2}}<\frac{\alpha \beta \theta}{\theta\left(\alpha+\kappa^{2}\right)-\alpha} .
\end{aligned}
$$

Given that $f^{\prime}\left(c_{\pi}^{c g}\right)=-\frac{2 p_{2}}{p_{1}} c_{\pi}^{c g}>0$ for $c_{\pi}^{c g} \in[0,1], f\left(c_{\pi}^{c g}\right)$ is strictly increasing in the interval $\left[0 ; \frac{\alpha \beta \theta}{\theta\left(\alpha+\kappa^{2}\right)-\alpha}\right]$. This property and the fact that $\left.f\left(c_{\pi}^{c g}\right):\left[0 ; \frac{\alpha \beta \theta}{\theta\left(\alpha+\kappa^{2}\right)-\alpha}\right] \rightarrow\right] 0 ; \frac{\alpha \beta \theta}{\theta\left(\alpha+\kappa^{2}\right)-\alpha}\left[\right.$ imply that there is a unique solution for $c_{\pi}^{c g}$ so that $0<c_{\pi}^{c g}<\frac{\alpha \beta \theta}{\theta\left(\alpha+\kappa^{2}\right)-\alpha}$.

The case where $\gamma=0$. We obtain by substituting $\gamma=0$ into (36)-(38) :

$$
\begin{gathered}
A_{11} \equiv \frac{\theta\left(\alpha+\kappa^{2}\right)-\alpha}{\beta\left[\theta\left(\alpha+\kappa^{2}\right)-\alpha\right]}=\frac{1}{\beta}, \\
A_{12} \equiv-\frac{\alpha \theta(1-\beta)}{\theta\left(\alpha+\kappa^{2}\right)-\alpha}, \\
P_{1} \equiv-\frac{\alpha \theta}{\beta\left[\theta\left(\alpha+\kappa^{2}\right)-\alpha\right]} .
\end{gathered}
$$

It follows from (42)-(43) that

$$
\begin{aligned}
c_{\pi}^{c g} & =\frac{\alpha \beta \theta}{\theta\left(\alpha+\kappa^{2}\right)-\alpha}, \\
d_{\pi}^{c g} & =\frac{\alpha \theta}{\theta\left(\alpha+\kappa^{2}\right)-\alpha} .
\end{aligned}
$$

The case where $\gamma=1$. Inserting $\gamma=1$ into (36)-(38) yields

$$
\begin{aligned}
& A_{11} \equiv \frac{\theta\left(\alpha+\kappa^{2}+\alpha \beta^{3}\right)-\alpha}{\alpha \beta^{2} \theta}, \\
& A_{12} \equiv-\frac{1}{\beta^{\prime}} \\
& P_{1} \equiv-\frac{1}{\beta^{2}} .
\end{aligned}
$$

Substituting the latter into (36)-(38) leads to $p_{2}=\theta \alpha \beta^{2}>0, p_{1}=\alpha-\kappa^{2} \theta-\alpha \theta-\theta \alpha \beta^{3}<0$ and $p_{0}=\alpha \beta \theta>0$, and hence

$$
\begin{aligned}
& c_{\pi}^{c g}=\frac{\theta\left(\alpha+\kappa^{2}\right)-\alpha+\theta \alpha \beta^{3}-\sqrt{\left[\theta\left(\alpha+\kappa^{2}\right)-\alpha+\theta \alpha \beta^{3}\right]^{2}-4 \theta^{2} \alpha^{2} \beta^{3}}}{2 \theta \alpha \beta^{2}}, \\
& d_{\pi}^{c g}=\frac{\alpha \theta}{\theta\left(\alpha+\kappa^{2}\right)-\alpha+\beta^{2} \theta \alpha\left(\beta-c_{\pi}^{c g}\right)} .
\end{aligned}
$$




\section{A.3 The effects of learning}

Deriving $p_{0}, p_{1}$ and $p_{2}$ with respect to $\gamma$ and using (50), we get:

$$
\begin{aligned}
\frac{\partial p_{0}}{\partial \gamma} & =\alpha \beta^{2} \theta[(2-\beta)(1-\gamma)+\gamma \beta]>0 \\
\frac{\partial p_{1}}{\partial \gamma} & =-\beta \frac{\partial p_{2}}{\partial \gamma}-\frac{\theta\left(\alpha+\kappa^{2}\right)-\alpha}{\theta \alpha \beta} \frac{\partial p_{0}}{\partial \gamma}<0 \\
\frac{\partial p_{2}}{\partial \gamma} & =\beta\left\{\left(\kappa^{2} \theta-\alpha\right)(1-2 \gamma)+\theta \alpha[1-2 \gamma(1-\beta)]\right\} \\
& =-\frac{1}{\partial \gamma}-\frac{\partial p_{1}}{\theta \alpha \beta} \frac{\theta\left(\alpha+\kappa^{2}\right)-\alpha}{\partial \gamma}
\end{aligned}
$$

Deriving $c_{\pi}^{c g}$ with respect to $\gamma$ yields:

$$
\frac{\partial c_{\pi}^{c g}}{\partial \gamma}=\frac{\left[-\frac{\partial p_{1}}{\partial \gamma}-\frac{1}{\sqrt{p_{1}^{2}-4 p_{2} p_{0}}}\left(p_{1} \frac{\partial p_{1}}{\partial \gamma}-2 p_{0} \frac{\partial p_{2}}{\partial \gamma}-2 p_{2} \frac{\partial p_{0}}{\partial \gamma}\right)\right] p_{2}-\left(-p_{1}-\sqrt{p_{1}^{2}-4 p_{2} p_{0}}\right) \frac{\partial p_{2}}{\partial \gamma}}{2 p_{2}^{2}},
$$

which can be rewritten, using $\frac{\partial p_{2}}{\partial \gamma}=-\frac{1}{\partial \gamma}-\frac{\partial p_{1}}{\beta} \frac{\theta\left(\alpha+\kappa^{2}\right)-\alpha}{\theta \alpha \beta} \frac{\partial p_{0}}{\partial \gamma}$ and the definition of $p_{0}, p_{1}$ and $p_{2}, p_{1}=-\beta p_{2}-$ $\frac{\theta\left(\alpha+\kappa^{2}\right)-\alpha}{\theta \alpha \beta} p_{0}$ and $c_{\pi}^{c g}=\frac{-p_{1}-\sqrt{p_{1}^{2}-4 p_{2} p_{0}}}{2 p_{2}}$ and after fastidious arrangements of terms, as: ${ }^{19}$

$$
\frac{\partial c_{\pi}^{c g}}{\partial \gamma}=\frac{1-\frac{\theta\left(\alpha+\kappa^{2}\right)-\alpha}{\theta \alpha \beta} c_{\pi}^{c g}}{\beta p_{2} \sqrt{p_{1}^{2}-4 p_{2} p_{0}}}\left(p_{0} \frac{\partial p_{1}}{\partial \gamma}-p_{1} \frac{\partial p_{0}}{\partial \gamma}\right) .
$$

Using $c_{\pi}^{c g}<\frac{\theta \alpha \beta}{\theta\left(\alpha+\kappa^{2}\right)-\alpha}$, we obtain: $1-\frac{\theta \alpha \beta}{\theta\left(\alpha+\kappa^{2}\right)-\alpha} c_{\pi}^{c g}>1-\frac{\theta \alpha \beta}{\theta\left(\alpha+\kappa^{2}\right)-\alpha} \frac{\theta\left(\alpha+\kappa^{2}\right)-\alpha}{\theta \alpha \beta}=0$. To determine the sign of $H \equiv$ $p_{0} \frac{\partial p_{1}}{\partial \gamma}-p_{1} \frac{\partial p_{0}}{\partial \gamma}$, we first check its value for $\gamma=1$ and then its derivative with respect to $\gamma$.

It is easy to check that for $\gamma=1$, we have

$$
H=-\alpha \beta^{3} \theta\left\{\alpha-\theta\left[\kappa^{2}-\alpha \beta\left(1-\beta^{2}\right)\right]\right\}<0
$$

if $\kappa^{2}-\alpha \beta\left(1-\beta^{2}\right)<0$; otherwise, we must impose:

$$
\theta>\frac{\alpha}{\kappa^{2}-\alpha \beta\left(1-\beta^{2}\right)}>\frac{\alpha}{\kappa^{2}}
$$

Deriving $H$ with respect to $\gamma$ yields

$$
\begin{aligned}
\frac{\partial H}{\partial \gamma} & =p_{0} \frac{\partial^{2} p_{1}}{\partial^{2} \gamma}-p_{1} \frac{\partial^{2} p_{0}}{\partial^{2} \gamma} \\
& =2 \alpha \theta \beta^{3}(1-\beta)\left\{[1-\gamma(1-\gamma \beta)]\left\{\theta\left[\kappa^{2}+\alpha(1-\beta)\right]-\alpha\right\}+\beta^{3} \gamma^{2} \alpha \theta\right\}>0 .
\end{aligned}
$$

Consequently, given that $H<0$ for $\gamma=1$ and $\frac{\partial H}{\partial \gamma}>0$ for $\forall \gamma \in[0,1]$, we conclude that

$$
\frac{\partial c_{\pi}^{c g}}{\partial \gamma}<0
$$

Deriving $d_{\pi}^{c g}$ given by (53) with respect to $\gamma$ yields:

$$
\begin{aligned}
\frac{\partial d_{\pi}^{c g}}{\partial \gamma} & =\frac{\kappa^{2} \theta-\alpha}{\kappa \theta} \frac{\partial d_{x}^{c g}}{\partial \gamma}=-\frac{\kappa^{2} \theta-\alpha}{\sigma \kappa \theta} \frac{\partial d_{r}^{c g}}{\partial \gamma} \\
& =\frac{-\alpha \beta \theta\left[\Phi-\gamma[\alpha \beta \gamma \theta+(1-\gamma) \Theta] \frac{\partial c_{\pi}^{c g}}{\partial \gamma}\right]}{\left[\Theta+\theta \alpha \gamma^{2} \beta^{2}\left(\beta-c_{\pi}^{c g}\right)+\gamma \beta(1-\gamma)\left(\theta \alpha \beta-\Theta c_{\pi}^{c g}\right)\right]^{2}}
\end{aligned}
$$


where $\Theta \equiv \theta\left(\alpha+\kappa^{2}\right)-\alpha$ and $\Phi \equiv 2 \alpha \beta \gamma \theta\left(\beta-c_{\pi}^{c g}\right)+(1-2 \gamma)\left(\alpha \beta \theta-\Theta_{\pi}^{c g}\right)$. Using the fact that $\beta$ is very close to one and hence $2 \beta-1>0$, and the fact that $c_{\pi}^{c g}<\frac{\theta \alpha \beta}{\theta\left(\alpha+\kappa^{2}\right)-\alpha}$, which implies that $\beta-c_{\pi}^{c g}>0$ and $\theta \alpha \beta-\Theta c_{\pi}^{c g}>0$, we find that

$$
\Phi=\beta \theta \alpha \gamma(2 \beta-1)\left(\beta-c_{\pi}^{c g}\right)+\beta \gamma\left(\theta \kappa^{2}-\alpha\right) c_{\pi}^{c g}+\beta(1-\gamma)\left\{\theta \alpha \beta-\left[\theta\left(\alpha+\kappa^{2}\right)-\alpha\right] c_{\pi}^{c g}\right\}>0 .
$$

It follows that

$$
\frac{\partial d_{\pi}^{c g}}{\partial \gamma}<0
$$

Using the definition of $c_{x}^{c g}, d_{x}^{c g}, c_{r}^{c g}$ and $d_{r}^{c g}$, it is straightforward to show the sign of their partial derivative with respect to $\gamma$.

\section{A.4 Effects of robustness}

Deriving $p_{0}, p_{1}$ and $p_{2}$ with respect to $\theta$ and using (50), we get:

$$
\begin{aligned}
& \frac{\partial p_{0}}{\partial \theta}=\alpha \beta\{1-\beta(1-\gamma)[1-\gamma(1-\beta)]\}=\frac{p_{0}}{\theta}>0, \\
& \left.\frac{\partial p_{1}}{\partial \theta}=-\kappa^{2}\left[1-\beta(1-\gamma)^{2}\right]-\alpha(1-\beta)\{1-\beta[1-\gamma(1-\beta)])\right\}-\frac{\partial p_{0}}{\partial \theta}-\frac{\partial p_{2}}{\partial \theta}<0, \\
& \frac{\partial p_{2}}{\partial \theta}=\gamma \beta\left\{\kappa^{2}(1-\gamma)+\alpha[1-\gamma(1-\beta)]\right\}>0 .
\end{aligned}
$$

Deriving $c_{\pi}^{c g}$ given by (52) with respect to $\theta$, and using $\frac{\partial p_{2}}{\partial \theta}=-\frac{1}{\beta} \frac{\partial p_{1}}{\partial \theta}-\frac{\left(\alpha+\kappa^{2}\right)}{\alpha \beta^{2}} \frac{\partial p_{0}}{\partial \theta}$, the definition of $p_{0}, p_{1}$ and $p_{2}$, $p_{1}=-\beta p_{2}-\frac{\theta\left(\alpha+\kappa^{2}\right)-\alpha}{\theta \alpha \beta} p_{0}$ and $c_{\pi}^{c g}=\frac{-p_{1}-\sqrt{p_{1}^{2}-4 p_{2} p_{0}}}{2 p_{2}}$ yield: ${ }^{20}$

$$
\frac{\partial c_{\pi}^{c g}}{\partial \theta}=\frac{1}{2 p_{2}^{2}}\left(I \frac{\partial p_{0}}{\partial \theta}+J \frac{\partial p_{1}}{\partial \theta}\right)
$$

where $I=\frac{2 p_{2}}{\sqrt{p_{1}^{2}-4 p_{2} p_{0}}}\left\{p_{2}+\frac{\left(\alpha+\kappa^{2}\right)}{\alpha \beta^{2}} p_{0}+\frac{\left(\alpha+\kappa^{2}\right)}{\alpha \beta^{2}} p_{1} c_{\pi}^{c g}\right\}$ and $J=\frac{2 p_{2}}{\beta \sqrt{p_{1}^{2}-4 p_{2} p_{0}}}\left[\left(1-\frac{\theta\left(\alpha+\kappa^{2}\right)-\alpha}{\theta \alpha \beta} c_{\pi}^{c g}\right) p_{0}\right]$. Using these definitions and the expressions of $\frac{\partial p_{0}}{\partial \theta}$ and $\frac{\partial p_{1}}{\partial \theta}$ derived in the above, we obtain:

$$
\begin{aligned}
\frac{\partial c_{\pi}^{c g}}{\partial \theta} & =\frac{\left(-\frac{\partial p_{1}}{\partial \theta}-\frac{1}{2} \frac{p_{1} \frac{\partial p_{1}}{\partial \theta}-4 p_{0} \frac{\partial p_{2}}{\partial \theta}-4 p_{2} \frac{\partial p_{0}}{\partial \theta}}{\sqrt{p_{1}^{2}-4 p_{2} p_{0}}}\right) p_{2}-\left(-p_{1}-\sqrt{p_{1}^{2}-4 p_{2} p_{0}}\right) \frac{\partial p_{2}}{\partial \theta}}{2 p_{2}^{2}} \\
& =\frac{\left(-\frac{\partial p_{1}}{\partial \theta}-\frac{1}{2} \frac{p_{1} \frac{\partial p_{1}}{\partial \theta}-4 p_{0} \frac{\partial p_{2}}{\partial \theta}-4 p_{2} \frac{\partial p_{0}}{\partial \theta}}{\sqrt{p_{1}^{2}-4 p_{2} p_{0}}}\right)}{2 p_{2}}-\frac{1}{p_{2}} c_{\pi}^{c g} \frac{\partial p_{2}}{\partial \theta} .
\end{aligned}
$$

Using $p_{1}=-\beta p_{2}-\frac{\theta\left(\alpha+\kappa^{2}\right)-\alpha}{\theta \alpha \beta} p_{0}$, the definition of $p_{0}, p_{1}$ and $p_{2}$, we can show that $p_{0} \frac{\partial p_{2}}{\partial \theta}-p_{2} \frac{\partial p_{0}}{\partial \theta}>0$ and hence

$$
\frac{\partial c_{\pi}^{c g}}{\partial \theta}=-\frac{1}{2 p_{2}^{2}} \frac{2 p_{2}}{\sqrt{p_{1}^{2}-4 p_{2} p_{0}}}\left\{\left[1-\frac{\theta\left(\alpha+\kappa^{2}\right)-\alpha}{\theta \alpha \beta} c_{\pi}^{c g}\right]\left(p_{0} \frac{\partial p_{2}}{\partial \theta}-p_{2} \frac{\partial p_{0}}{\partial \theta}\right)+\frac{1}{\theta \beta} c_{\pi}^{c g} p_{2} \frac{\partial p_{0}}{\partial \theta}\right\}<0 .
$$

Deriving $d_{\pi}^{c g}$ given by (53) with respect to $\theta$ yields

$$
\frac{\partial d_{\pi}^{c g}}{\partial \theta}=\frac{-\alpha^{2}\left[1-\beta \gamma(1-\gamma) c_{\pi}^{c g}\right]+\alpha \theta\left\{\theta \alpha \gamma^{2} \beta^{2}+\gamma \beta(1-\gamma)\left[\theta\left(\alpha+\kappa^{2}\right)-\alpha\right]\right\} \frac{\partial c_{\pi}^{c g}}{\partial \theta}}{\left\{\theta\left(\alpha+\kappa^{2}\right)-\alpha+\theta \alpha \gamma^{2} \beta^{2}\left(\beta-c_{\pi}^{c g}\right)+\gamma \beta(1-\gamma)\left\{\theta \alpha \beta-\left[\theta\left(\alpha+\kappa^{2}\right)-\alpha\right] c_{\pi}^{c g}\right\}\right\}^{2}}<0 .
$$


Deriving $c_{x}^{c g}, d_{x}^{c g}, c_{r}^{c g}$ and $d_{r}^{c g}$ with respect to $\theta$ leads to

$$
\begin{gathered}
\frac{\partial c_{x}^{c g}}{\partial \theta}=-\frac{1}{\sigma} \frac{\partial c_{r}^{c g}}{\partial \theta}=\frac{\kappa \alpha}{\left(\kappa^{2} \theta-\alpha\right)^{2}}\left(\beta-c_{\pi}^{c g}\right)+\frac{\kappa \theta}{\kappa^{2} \theta-\alpha} \frac{\partial c_{\pi}^{c g}}{\partial \theta} \\
\frac{\partial d_{x}^{c g}}{\partial \theta}=-\frac{1}{\sigma} \frac{\partial d_{r}^{c g}}{\partial \theta}=\frac{\alpha \kappa}{\left(\kappa^{2} \theta-\alpha\right)^{2}}\left(1-d_{\pi}^{c g}\right)+\frac{\kappa \theta}{\kappa^{2} \theta-\alpha} \frac{\partial d_{\pi}^{c g}}{\partial \theta} .
\end{gathered}
$$

To ensure that $\frac{\partial c_{x}^{c g}}{\partial \theta}=-\frac{1}{\sigma} \frac{\partial c_{r}^{c g}}{\partial \theta}>0$, and $\frac{\partial d_{x}^{c g}}{\partial \theta}=-\frac{1}{\sigma} \frac{\partial d_{r}^{c g}}{\partial \theta}>0$, we must have $\frac{\partial c_{\pi}^{c g}}{\partial \theta}>-\frac{\alpha\left(\beta-c_{\pi}^{c g}\right)}{\theta\left(\kappa^{2} \theta-\alpha\right)}$ and $\frac{\partial d_{\pi}^{c g}}{\partial \theta}>-\frac{\alpha\left(1-d_{\pi}^{c g}\right)}{\theta\left(\kappa^{2} \theta-\alpha\right)}$, respectively. For standard parameters values, these conditions are checked.

\section{Notes}

1 The attenuation principle is also called "conservatism principle" by Blinder (1998). This conventional wisdom has it that if the central bank was not sure about the marginal effects on economic variables of a change in its instrument, it should be cautious in the sense that it changes the instrument less than in the absence of parameter uncertainty. In the literature on robust monetary policy, the meaning of "cautious" is reversed such that "being cautious (or precautionary)" actually signifies "to do more", i.e. the policymaker tries to avoid bad outcomes in the future by responding more aggressively to shocks today (Söderström 2002; Giannoni 2007).

2 Adam and Woodford (2012) have combined the possibility of a deviation from rational expectations and a concern for model robustness by considering that private sector beliefs are not model-consistent, and the CB does not know exactly how these beliefs are formed. Having a preference for robustness with respect to this particular type of misspecification, the CB should conduct a monetary policy that shows greater resistance to surprise increases in inflation than would be considered optimal if the private sector forms RE.

3 Empirical studies show that consumers react sluggishly to persistent shifts in the inflation rate, see Trehan (2011) and Trehan and Lynch (2013), meaning that they slowly adapt their inflation forecast.

4 Many arguments and proofs of this paper follow quite closely the lines of Molnár and Santoro (2014).

5 Bask and Proaño (2016) do not use the robust control approach but consider various scenarios with different parameters values.

6 There is an alternative assumption according to which the CB acts as a Stackelberg leader, and sets its policy taking account of the malevolent agent's choice of the specification errors (Leitemo and Söderström 2008). If we had assumed that the malevolent agent is here the Stackelberg leader, the approach in terms of model misspecifications would lose its interest since the CB could adjust its policy according to the scenario designed by the nature/malevolent agent (Hansen and Sargent 2003).

7 Issues of learning when monetary policy is under commitment have been studied by Evans and Honkapohja (2006) showing that both RE commitment equilibrium (RECE) and RE discretionary equilibrium (REDE) are attainable, and Mele, Molnár, and Santoro (2014) finding that the optimal monetary policy drives the economy far from the RECE but to the REDE.

8 The modern literature on learning algorithms was pioneered by Marcet and Sargent (1989) who studied the convergence to RE equilibrium when agents form expectations using least-squares learning. For a survey of the literature, see Evans and Honkapohja (2001).

9 The limitation of learning process described in (6) and (7) is that agents focus on past information and the forecast with one period ahead.

ㅍ Alternatively, Preston (2005) considers that long-horizon expectations matter for monetary policy decision.

10 It is to notice that decreasing-gain learning is often the first approach adopted by most economic agents (Berardi and Galimberti 2013).

11 In the approximating model considered by Leitemo and Söderström (2008), inflation is less volatile while the output gap and the interest rate are more volatile.

12 This condition implies that the second-order condition regarding $h$ for the min-max problem of the CB is verified, i.e. $\frac{\partial^{2} \mathscr{L}_{t}^{C B}}{\partial^{2} h_{t}}=-\theta+$ $\frac{\alpha}{\alpha+\kappa^{2}}<0$. If this condition is not verified, the fictitious malevolent agent will choose $h_{t} \rightarrow \infty$.

13 An alternative approach is to solve for the equilibrium by considering the "approximating model" (Leitemo and Söderström 2008). The latter is based on the idea that the CB sets policy and agents form expectations to reflect misspecification in the worst-case model, but there is no such misspecification in practice in the sense that misspecification $h_{t}$ is null.

14 Indeed, (18) implies that $\frac{\partial^{2} \mathscr{L}_{t}^{C B}}{\partial^{2} h_{t}}=-\theta+\frac{\partial \lambda_{1, t}}{\partial h_{t}}$. Using (19), (25) and (1), we obtain $\frac{\partial \lambda_{1, t}}{\partial h_{t}}=-\frac{\kappa^{2} \theta}{\alpha}+1+\gamma \frac{\partial \lambda_{3, t}}{\partial h_{t}}$. Using (24), (25) and (32), we can show that $\frac{\partial \lambda_{3, t}}{\partial h_{t}}=0$. Therefore $\frac{\partial^{2} \mathscr{L}_{t}^{C B}}{\partial^{2} h_{t}}<0$. Leads to $\theta>\frac{\alpha}{\alpha+\kappa^{2}}$. We remark that the lower bound for $\theta$ implied by the existence of optimal solution of the malevolent agent's maximization problem is the same when agents are learning than under RE (see footnote 11).

15 We will show why this condition should be imposed when we solve the ALM for the output gap.

16 See Evans and Honkapohja (2001) for a presentation of different learning algorithms.

17 The relaxation of the assumption of constant-gain learning is justified by Milani (2014) who shows that private agents appear to have often switched to constant-gain learning, with a high constant gain, during most of the 1970s and until the early 1980s, while reverting to a decreasing-gain later on.

18 See Brunnermeier, Eisenbach, and Sannikov (2013) for a survey of the literature.

19 More details are given in a technical appendix that can be obtained upon request.

20 More details are given in the technical appendix.

Article note: A technical appendix is available upon request to the author. 


\section{References}

Adam, K., and M. Woodford. 2012. "Robustly Optimal Monetary Policy in a Micro-founded New Keynesian Model." Journal of Monetary Economics 59 (5): 468-487.

Airaudo, M., S. Nisticò, and L.-F. Zanna. 2015. “Learning, Monetary Policy, and Asset Prices.” Journal of Money, Credit and Banking 47: 1273-1307.

André, M. C., and M. Dai. 2017. “Is Central Bank Conservatism Desirable Under Learning?” Economic Modelling 60: 281-296.

Bask, M., and C. R. Proaño. 2016. “Optimal Monetary Policy Under Learning and Structural Uncertainty in a New Keynesian Model with a Cost Channel and Inflation Inertia." Journal of Economic Dynamics and Control 69: 112-126.

Berardi, M., and J. K. Galimberti. 2013. "A Note on Exact Correspondences Between Adaptive Learning Algorithms and the Kalman Filter." Economics Letters 118 (1): 139-142.

Blanchard, O. J., and C. M. Kahn. 1980. “The Solution of Linear Difference Models Under Rational Expectations.” Econometrica 48 (5): 1305-1311.

Blinder, A. S. 1998. Central Banking in Theory and Practice. Cambridge, MA: MIT Press.

Brainard, W. 1967. "Uncertainty and the Effectiveness of Policy." American Economic Review 57 (2): 411-425.

Brunnermeier, M. K., T. Eisenbach, and Y. Sannikov. 2013. "Macroeconomics with Financial Frictions: A Survey." Advances in Economics and Econometrics, Tenth World Congress of the Econometric Society. New York: Cambridge University Press.

Bullard, J., and K. Mitra. 2002. "Learning About Monetary Policy Rules." Journal of Monetary Economics 49 (6): 1105-1129.

Caputo, R., J. P. Medina, and C. Soto. 2011. “The Financial Accelerator Under Learning and the Role of Monetary Policy." In Monetary Policy Under Financial Turbulence, 1st ed., vol. 16, chapter 7, edited by Luis Felipe Céspedes, Roberto Chang and Diego Saravia, 185-218. Santiago: Central Bank of Chile.

Clarida, R., J. Gali, and M. Certler. 1999. “The Science of Monetary Policy: A New Keynesian Perspective." Journal of Economic Literature 37: 1661-1707.

da Gama Machado, V. 2013. "Monetary Policy Rules, Asset Prices and Adaptive Learning." Journal of Financial Stability 9 (3): 251-258.

Dai, M., and E. Spyromitros. 2010. "Accountability and Transparency About Central Bank Preferences for Model Robustness." Scottish Journal of Political Economy 57 (2): 212-237.

Evans, G. W., and S. Honkapohja. 2001. Learning and Expectations in Macroeconomics. Princeton, N]: Princeton University Press.

Evans, C. W., and S. Honkapohja. 2003. “Adaptive Learning and Monetary Policy Design.” Journal of Money, Credit and Banking 35 (6): 1045-1072.

Evans, G. W., and S. Honkapohja. 2006. “Monetary Policy, Expectations and Commitment." Scandinavian Journal of Economics 108 (1): 15-38.

Evans, C. W., and S. Honkapohja. 2009. “Learning and Macroeconomics.” Annual Review of Economics 1: 421-449.

Ciannoni, M. P. 2002. “Does Model Uncertainty Justify Caution? Robust Optimal Monetary Policy in a Forward-Looking Model.” Macroeconomic Dynamics 6 (1): 111-144.

Giannoni, M. P. 2007. "Robust Optimal Monetary Policy in a Forward-Looking Model with Parameter and Shock Uncertainty." Journal of Applied Econometrics 22 (1): 179-213.

Giannoni, M. P., and M. Woodford. 2002. “Optimal Interest-Rate Rules: I. Ceneral Theory.” NBER Working Paper No. 9419. National Bureau of Economic Research

Giordani, P., and P. Söderlind. 2004. "Solution of Macromodels with Hansen-Sargent Robust Policies: Some Extensions." Journal of Economic Dynamics and Control 28 (12): 2367-2397.

Conzalez, F., and A. Rodriguez. 2013. “Monetary Policy Under Time-Varying Uncertainty Aversion." Computational Economics 41 (1): 125-150.

Hansen, L. P., and T. J. Sargent. 2001. "Acknowledging Misspecification in Macroeconomic Theory." Review of Economic Dynamics 4 (3): $519-535$.

Hansen, L. P., and T. J. Sargent. 2003. "Robust Control of Forward-Looking Models."Journal of Monetary Economics 50: 581-604.

Hansen, L. P., and T. J. Sargent. 2007. Robustness. Princeton, N]: Princeton University Press.

Hollmayr, J., and M. Kühl. 2016. "Imperfect Information About Financial Frictions and Consequences for the Business Cycle." Review of Economic Dynamics 22: 179-207.

Honkapohja, S. 2016. "Monetary Policies to Counter the Zero Interest Rate: An Overview of Research." Empirica 43 (2): 235-256.

Honkapohja, S., and K. Mitra. 2015. "Comparing Inflation and Price-Level Targeting: The Role of Forward Guidance and Transparency." The Manchester School 83 (S2): 27-59.

Leitemo, K., and U. Söderström. 2008. “Robust Monetary Policy in the New-Keynesian Framework.” Macroeconomic Dynamics 12 (S1): $126-135$.

Marcet, A., and T. J. Sargent. 1989. “Least-Squares Learning and the Dynamics of Hyperinflation.". In Barnett, William, John Ceweke, and Karl Shell (Eds.), Economic Complexity: Chaos, Sunspots, Bubbles, and Nonlinearity. 119-137. Cambridge: Cambridge University Press.

Marcet, A., and J. P. Nicolini. 2003. "Recurrent Hyperinflations and Learning." American Economic Review 93: 1476-1498.

McCallum, B. 1983. “On Non-uniqueness in Rational Expectation Models - An Attempt at Perspective." Journal of Monetary Economics 11: 139-168.

Mele, A., K. Molnár, and S. Santoro. 2014. “The Suboptimality of Commitment Equilibrium When Agents are Learning.” Unpublished paper. University of Oxford.

Milani, F. 2008. “Learning, Monetary Policy Rules, and Macroeconomic Stability." Journal of Economic Dynamics and Control 32 (10): $3148-3165$.

Milani, F. (2014). “Learning and Time-Varying Macroeconomic Volatility.” Journal of Economic Dynamics and Control 47 (10): 94-114.

Molnár, K., and S. Santoro. 2014. “Optimal Monetary Policy When Agents Are Learning." European Economic Review 66: 39-627.

Moore, B. 2016. "Anticipated Disinflation and Recession in the New Keynesian Model Under Learning." Economics Letters 142: 49-52.

Onatski, A., and ]. H. Stock. 2002. "Robust Monetary Policy Under Model Uncertainty in a Small Model of the U.S. Economy." Macroeconomic Dynamics 6 (1): 85-110.

Orphanides, A., and J. C. Williams. 2007. “Robust Monetary Policy with Imperfect Knowledge.” Journal of Monetary Economics 54 (5): $1406-1435$. 
Orphanides, A., and J. C. Williams. 2008. "Learning, Expectations Formation, and the Pitfalls of Optimal Control Monetary Policy." Journal of Monetary Economics 55 (Supplement): S80-S96.

Qin, L., M. Sidiropoulos, and E. Spyromitros. 2013. "Robust Monetary Policy Under Model Uncertainty and Inflation Persistence." Economic Modelling 30 (C): 721-728.

Preston, B. 2005. “Learning About Monetary Policy Rules When Long-Horizon Expectations Matter." International Journal ofCentral Banking 1 (2): $81-126$.

Rotemberg, J. J., and M. Woodford. 1997. "An Optimization-Based Econometric Framework for the Evaluation of Monetary Policy." In NBER Macroeconomics Annual, edited by Ben S. Bernanke and Julio J. Rotemberg. Cambridge, MA: The MIT Press.

Rychalovska, Y., S. Slobodyan, and R. Wouters. 2015. “Estimating DSCE Model with Financial Frictions and Different Forms of Expectations Formation." Manuscript.

Schmidt-Hebbel, K., and C. E. Walsh. 2009. "Monetary Policy Under Uncertainty and Learning: An Overview." In Monetary Policy Under Uncertainty and Learning, edited by Klaus Schmidt-Hebbel, Carl E. Walsh and Norman Loayza, Edition 1, vol. 13, 1-25. Santiago: Central Bank of Chile.

Söderström, U. 2002. “Monetary Policy with Uncertain Parameters.” Scandinavian Journal of Economics 104 (1): 125-145.

Slobodyan, S., and R. Wouters. 2012. “Learning in an Estimated Medium-Scale DSCE Model.” Journal of Economic Dynamics and Control 36 (1): 26-46.

Tetlow, R. J., and P. von zur Muehlen. 2004. "Avoiding Nash Inflation: Bayesian and Robust Responses to Model Uncertainty." Review of Economic Dynamics 7 (4): 869-899.

Tillmann, P. 2009. "The Stabilization Bias and Robust Monetary Policy Delegation." Journal of Macroeconomics 31 (4): $730-734$.

Tillmann, P. 2014. “Robust Monetary Policy, Optimal Delegation and Misspecified Potential Output." Economics Letters 123 (2): 244-247.

Trehan, B. 2011. "Household Inflation Expectations and the Price of Oil: It's Déjà Vu All Over Again." FRBSF Economic Letter 16 (May 23).

Trehan, B., and M. Lynch. 2013. “Consumer Inflation Views in Three Countries.” FRBSF Economic Letter 2013-35, Federal Reserve Bank of San Francisco.

Woodford, M. 1999. “Optimal Monetary Policy Inertia.” The Manchester School Suppl. 67: 1-35. 